Expert Meeting:

Recommended Approaches to Humidity Control in High Performance Homes

Armin Rudd

Building Science Corporation (BSC)

July 2013 


\section{NOTICE}

This report was prepared as an account of work sponsored by an agency of the United States government. Neither the United States government nor any agency thereof, nor any of their employees, subcontractors, or affiliated partners makes any warranty, express or implied, or assumes any legal liability or responsibility for the accuracy, completeness, or usefulness of any information, apparatus, product, or process disclosed, or represents that its use would not infringe privately owned rights. Reference herein to any specific commercial product, process, or service by trade name, trademark, manufacturer, or otherwise does not necessarily constitute or imply its endorsement, recommendation, or favoring by the United States government or any agency thereof. The views and opinions of authors expressed herein do not necessarily state or reflect those of the United States government or any agency thereof.

Available electronically at http://www.osti.gov/bridge

Available for a processing fee to U.S. Department of Energy

and its contractors, in paper, from:

U.S. Department of Energy

Office of Scientific and Technical Information

P.O. Box 62

Oak Ridge, TN 37831-0062

phone: 865.576 .8401

fax: 865.576.5728

email: mailto:reports@adonis.osti.gov

Available for sale to the public, in paper, from:

U.S. Department of Commerce

National Technical Information Service

5285 Port Royal Road

Springfield, VA 22161

phone: 800.553 .6847

fax: 703.605.6900

email: orders@ntis.fedworld.gov

online ordering: http://www.ntis.gov/ordering.htm

Printed on paper containing at least $50 \%$ wastepaper, including $20 \%$ postconsumer waste 


\title{
Expert Meeting: Recommended Approaches to Humidity Control in High Performance Homes
}

\author{
Prepared for: \\ The National Renewable Energy Laboratory \\ On behalf of the U.S. Department of Energy's Building America Program \\ Office of Energy Efficiency and Renewable Energy \\ 15013 Denver West Parkway \\ Golden, CO 80401 \\ NREL Contract No. DE-AC36-08GO28308 \\ Prepared by: \\ Armin Rudd \\ Building Science Corporation \\ 30 Forest Street \\ Somerville, MA 02143 \\ NREL Technical Monitor: Cheryn Engebrecht \\ Prepared under Subcontract No. KNDJ-0-40337-00
}

July 2013 


\section{Acknowledgements}

The author appreciates the presentations made by the invited speakers including: Hugh Henderson of CDH Energy Corp.; Philip Fairey of Florida Solar Energy Center; and Michael Sypolt of IBACOS.

\section{Definitions}

BSC Building Science Corporation

AHRI Air Conditioning Heating and Refrigeration Institute

AHAM Association of Home Appliance Manufacturers

RH Relative humidity

NRC Natural Resources Canada

USDOE United States Department of Energy

NREL National Renewable Energy Laboratory

CFI Central-fan-integrated [supply ventilation]

ERV Energy recovery ventilator

HRV Heat recovery ventilator 
[This page left blank] 


\section{Table of Contents}

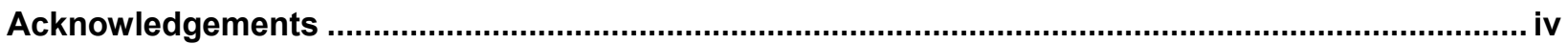

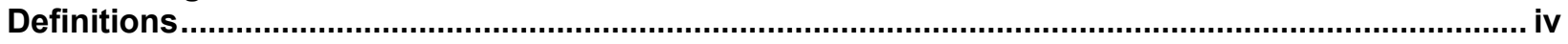

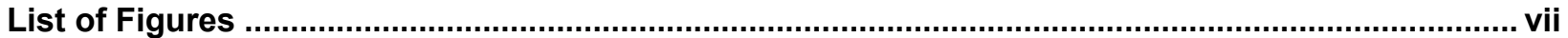

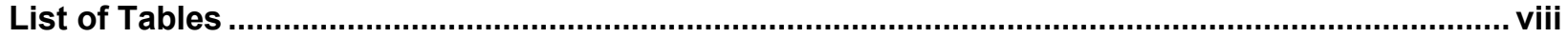

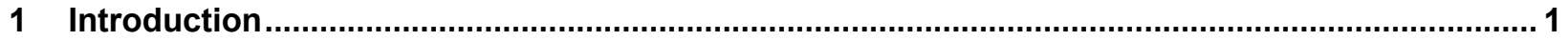

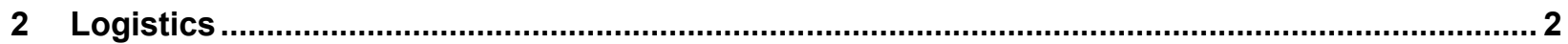

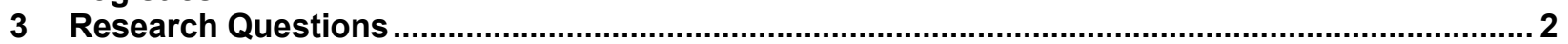

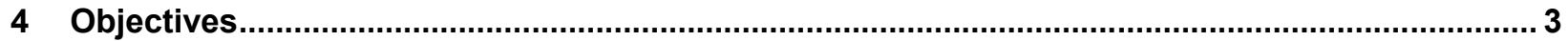

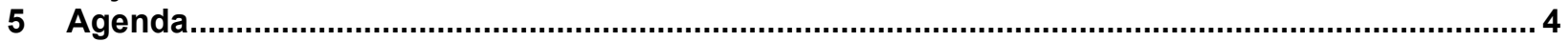

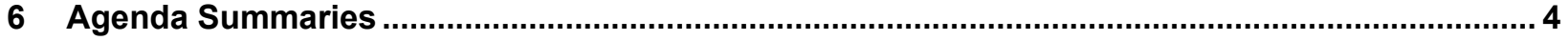

ASHRAE RP 1449: Energy Efficiency and Cost Assessment of Humidity Control Options

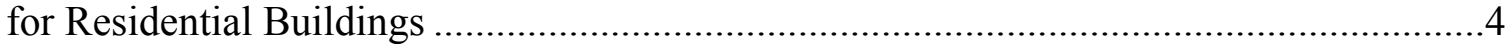

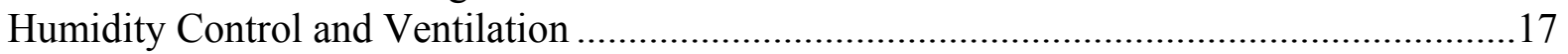

EnergyPlus Humidity Control and Ventilation Modeling Analysis ....................................25

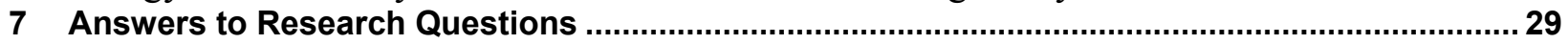

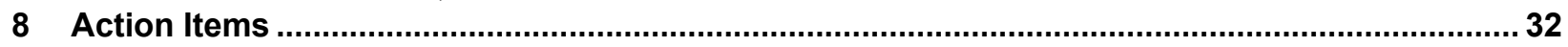

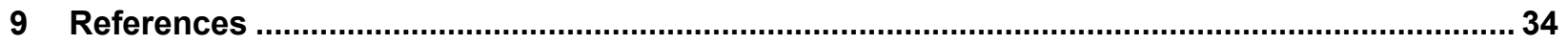




\section{List of Figures}

Figure 1. Computer modeling improvements allowing more realistic simulation results 5

Figure 2. Simulation framework that allows for multiple temperature control, humidity control, ventilation, and fan recirculation systems to operate at the same time......................................5

Figure 3. Simulation framework that allows for multiple temperature control, humidity control, ventilation, and fan recirculation systems to operate at the same time...................................... 6

Figure 4. Calculation of the combined airflow of infiltration, duct leakage, and balanced and

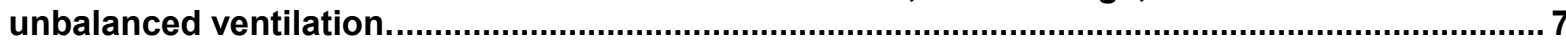

Figure 5. Conventional cooling system and indoor temperature and $\mathrm{RH}$ response with heating,

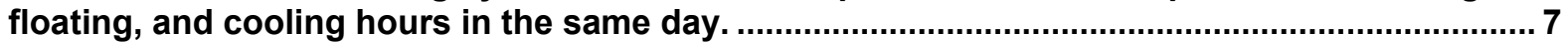

Figure 6. RH limit expressed as hours over $60 \% \mathrm{RH}$ and 4 hour events over $60 \% \mathrm{RH}$.................... 8

Figure 7. Impact of exhaust ventilation rate at $50 \%, 100 \%$ and $150 \%$ of the ASHRAE Standard $62.2-$

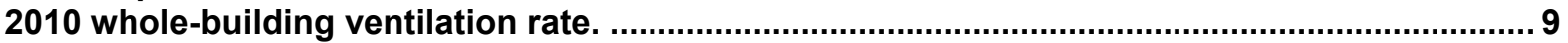

Figure 8. Simulation results for enhanced Systems modeled in HERS 70 level houses..................10

Figure 9. A check of the simulation response with moisture capacitance turned off (set to zero).. 11

Figure 10. Measured and simulated indoor vs. outdoor humidity trends with indoor moisture capacitance.

Figure 11. The impact of overcooling by three degrees "sweeps" the higher RH hours down and to the left.

Figure 12. Locating the air distribution system ducts inside conditioned space saves overall energy, but also increases the need for supplemental dehumidification.

Figure 13. In Miami, hours of elevated indoor humidity occur mostly in morning hours between late November and March.

Figure 14. Hours of elevated indoor humidity is strongly related to internal moisture gains and

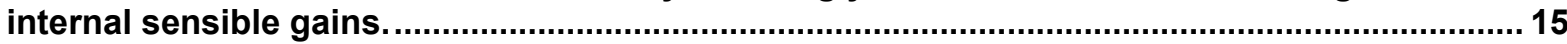

Figure 15. Hours of elevated indoor humidity is weakly related to moisture capacitance. ..............15

Figure 16. Hours of elevated indoor humidity is strongly related to heating setpoint..................... 16

Figure 17. Interactive Internet access is made available to retrieve customized sets of the simulation data.

Figure 18. Twelve cities and five climate zones simulated for a ventilation study including humidity impacts.

Figure 19. Outline of simulation prototype assumptions. .......................................................... 18

Figure 20. Internal sensible $(16.9 \mathrm{kWh} /$ day $)$ and latent gains schedule used in the simulations..... 19

Figure 21. For a week at the end of June and beginning of July on Orlando, the cooling system and space $\mathrm{RH}$ is showing an expected response.

Figure 22. Hours above 60\% RH for exhaust and ERV ventilation in Orlando. ................................. 20

Figure 23. Hours above $60 \%$ by climate and space conditioning mode. ...........................................21

Figure 24. Hours of elevated indoor RH is a strong function of the selected RH limit and climate. 22

Figure 25. ASHRAE 62.2-2010 addendum $r$ ventilation rate raises median $\mathrm{RH}$ compared to conventional dwelling without mechanical ventilation.

Figure 26. Predicted required moisture removal by supplemental dehumidification, by ventilation system type (energy recovery ventilator, exhaust, CFI supply).

Figure 27. Predicted cost of supplemental dehumidification.................................................... 24

Figure 28. NREL BEopt E+ program used to generate the building geometry and the base IDF files (input description).

Figure 29. Indoor RH vs. hour of year comparison between EnergyPlusPlus (blue symbols) and EnergyGauge USA (V3.0.01P) simulation results.

Figure 30. Energy consumption results by ventilation system type, ventilation rate, and building enclosure tightness.

Figure 31. An ERV reduces the number of hours with lowest and highest indoor RH, and a very large reduction in hours above 60\% RH compared to the FSEC and CDH models...................2 28

Figure 32. Window condensation potential during Orlando floating hours .....................................29

Figure 33. Overview of recommended dehumidifier test conditions. 


\section{List of Tables}

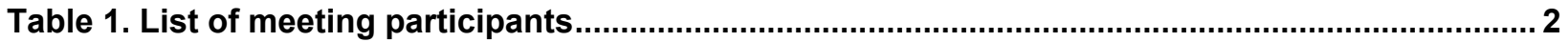

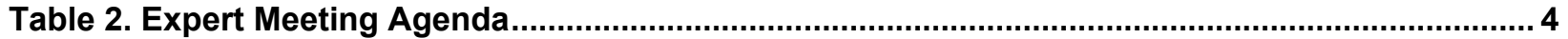

Unless otherwise noted, all tables were created by BSC. 


\section{Introduction}

As homes get more energy efficient, cooling systems have longer off-times due to lowered sensible heat gain. Overall, this is good, and produces a significant net energy and cost savings. However, this situation requires a change to conventional residential space conditioning system design in humid climates. While the sensible cooling load is lower, and can be dealt with in the conventional way, the latent (moisture) load in high performance homes remains nearly unchanged due to ventilation requirements and internal moisture generation by occupants and their activities. Therefore, at times when there is no need to lower the space air temperature, supplemental dehumidification will be required to maintain the relative humidity (RH) below acceptable levels.

Extensive field testing was done with builder partners in Texas and Florida in 2001 to 2007 (Rudd et al. 2003, BSC 2004, Rudd et al. 2005). That testing revealed that supplemental dehumidification was required in high performance Building America-level homes in order to maintain indoor RH below $60 \%$ year-round.

Off-the-shelf, stand-alone supplemental dehumidification systems were employed to address this problem while working with manufacturing partners on supplemental dehumidification integrated with the central space conditioning system. These companies began to offer integrated supplemental dehumidification solutions that allow year-round indoor $\mathrm{RH}$ control between $50 \%$ and $60 \%$. This was intended to enable further reduction in sensible cooling load. through further efficiency improvements, without the risk of elevated indoor humidity.

While these advancements have been important and needed in the residential space conditioning industry, supplemental dehumidification technology continues to improve and evolve, and the market for these products is still in its infancy. Design capacity prediction is subject to many unknowns and requires continued research to fully quantify.

Models that can accurately simulate the performance of humidity control systems in high performance buildings are needed to understand a wide range of scenarios related to the economics and operational success of low-energy homes with supplemental dehumidification. Simulation of supplemental dehumidification needs and performance in buildings is complex. It requires a model that controls both indoor temperature and $\mathrm{RH}$, and depends on many still somewhat sketchy inputs, such as: internal moisture generation and other moisture loads including effects of construction moisture drying and rain wetting under solar loading; building moisture capacitance and the effects of building material moisture adsorption/desorption under solar loading; and detailed dehumidification equipment performance maps. This capability is improving but still has a long way to go to be adequately integrated into commonly used building design and performance rating programs.

Building Science Corporation (BSC) hosted an expert meeting, "Recommended Approaches to Humidity Control in High Performance Homes," on October 16, 2012, in Westford, Massachusetts, to bring together experts in the field of residential humidity control to address modeling issues for dehumidification. 


\section{Logistics}

The expert meeting was held at the Westford Regency Inn and Conference Center, in Westford, Massachusetts, on October 16, 2012. The meeting was also made available to attendees by webinar, and was recorded. See Table 1 for a list of attendees.

Table 1. List of Meeting Participants.

\begin{tabular}{|l|l|l|l|l|}
\hline Last name & First name & Company & Email & $\begin{array}{c}\text { Attended In Person (P) } \\
\text { or by Webinar (W) }\end{array}$ \\
\hline & & & & \\
\hline Bergey & Daniel & BSC & daniel@buildingscience.com & P \\
\hline Bloemer & John & Research Products & jb@aprilaire.com & P \\
\hline Fairey & Philip & FSEC & pfairey@fsec.ucf.edu & P \\
\hline Harriman & Lew & Mason Grant & lewharriman@masongrant.com & P \\
\hline Henderson & Hugh & CDH Energy & hugh@cdhenergy.com & P \\
\hline Kerrigan & Philip & BSC & phil@buildingscience.com & P \\
\hline Metzger & Cheryn & NREL & Cheryn.Metzger@nrel.gov & P \\
\hline Pettit & Betsy & BSC & betsy@buildingscience.com & P \\
\hline Prahl & Duncan & IBACOS & dprahl@ibacos.com & P \\
\hline Rudd & Armin & BSC & arudd@buildingscience.com & P \\
\hline Sypolt & Michael & IBACOS & msypolt@ibacos.com & P \\
\hline Winkler & John & NREL & Jon.Winkler@nrel.gov & P \\
\hline Cottrell & Glenn & IBACOS & gcottrell@ibacos.com & W \\
\hline Dentz & Jordan & The Lew Partnership & jdentz@research-alliance.org & W \\
\hline Griffiths & Dianne & Steven Winter Associates & dgriffiths@swinter.com & W \\
\hline Grisolia & Anthony & IBACOS & agrisolia@ibacos.com & W \\
\hline Hudon & Kate & NREL & kate.hudon@nrel.gov & W \\
\hline Mittereder & Nick & Ibacos & nmittereder@ibacos.com & W \\
\hline Puttagunta & Srikanth & Steven Winter Associates & sri@swinter.com & W \\
\hline Tabares & Paulo & NREL & paulo.tabares@nrel.gov & W \\
\hline
\end{tabular}

\section{Research Questions}

A list of research questions that were compiled and distributed with the meeting invitation is as follows:

- What are the important humidity control conclusions from recent residential dehumidification systems modeling, with a wide range of building and equipment sensitivity, using a customized $<2$ minute time-step TRNSYS model with temperature and humidity control?

- What are the important humidity control conclusions from recent residential ventilation modeling efforts using the temperature and humidity control logic of the Energy Plus version of the NREL BEopt program?

- What are the important indoor humidity conclusions that can be drawn from recent residential ventilation modeling efforts using the temperature-only control logic of the FSEC EnergyGauge USA program? 
- How do the results from these different programs compare?

- Is it generally agreed that controlling to less than $60 \% \mathrm{RH}$ is the appropriate humidity control point for high performance homes, and why?

- Is it generally agreed that annual hours above $60 \% \mathrm{RH}$ is the appropriate humidity control performance metric to use to compare system performance and to compare required supplemental dehumidification energy? Does that metric give generally the same result as looking at 4-hour and 8-hour events above $60 \% \mathrm{RH}$ ?

- For a range of climates, ventilation systems, and space conditioning equipment in high performance homes, what is the magnitude of hours above $60 \% \mathrm{RH}$, the magnitude of supplemental dehumidification energy required to control to less than $60 \% \mathrm{RH}$, the time of year occurrence of elevated indoor humidity and supplemental dehumidification, and the space conditioning mode (heating, cooling, floating) during which most periods of elevated indoor humidity and supplemental dehumidification occur?

\section{Objectives}

The topic of this meeting was "Recommended Approaches to Humidity Control in High Performance Homes," and focused on dehumidification requirements. Presentations and discussions centered on computer simulation and field experience with these systems, with the goal of developing foundational information to support the development of a Building America Measure Guideline on this topic.

The expert meeting was designed to bring together experts in the field of residential indoor humidity control by dehumidification to discuss the following objectives:

- Compare and contrast the state-of-the art in modeling residential supplemental dehumidification requirements in high performance homes.

- Come to agreement on an acceptable RH control system within a model and the primary metric to be used for evaluating the success of a given humidity control system.

- Quantitatively identify general trends as to the performance of, and cost to operate, supplemental dehumidification systems in high performance homes in humid climates. 


\section{Agenda}

Table 2 shows the expert meeting agenda.

Table 2. Expert Meeting Agenda.

\begin{tabular}{|c|c|c|}
\hline Time & Speaker & Topic \\
\hline $8: 00$ to $8: 10$ & $\begin{array}{l}\text { Armin Rudd } \\
\text { Building Science Corp }\end{array}$ & Welcome and Introduction \\
\hline $8: 10$ to $9: 00$ & $\begin{array}{l}\text { Hugh Henderson } \\
\text { CDH Energy Corp }\end{array}$ & $\begin{array}{l}\text { ASHRAE RP } 1449 \\
\text { Energy Efficiency and Cost Assessment of } \\
\text { Humidity Control Options for Residential Buildings }\end{array}$ \\
\hline 9:00 to 9:50 & $\begin{array}{l}\text { Philip Fairey } \\
\text { Florida Solar Energy Center }\end{array}$ & Humidity Control and Ventilation \\
\hline 9:50 to $10: 00$ & & Break \\
\hline $10: 00$ to $10: 50$ & $\begin{array}{l}\text { Michael Sypolt and Duncan } \\
\text { Prahl } \\
\text { IBACOS }\end{array}$ & $\begin{array}{l}\text { EnergyPlus Humidity Control and Ventilation Modeling } \\
\text { Analysis }\end{array}$ \\
\hline $10: 50$ to $12: 00$ & $\begin{array}{l}\text { Armin Rudd } \\
\text { Building Science Corp }\end{array}$ & $\begin{array}{l}\text { Facilitated Open Discussion, Action Items, and Final } \\
\text { Remarks }\end{array}$ \\
\hline
\end{tabular}

\section{Agenda Summaries}

Discussions occurred during and after each of the three invited presentations and in the facilitated discussion period that followed.

\section{ASHRAE RP 1449: Energy Efficiency and Cost Assessment of Humidity Control Options for Residential Buildings}

(Hugh Henderson, CDH Energy Corp.)

A number of fundamental computer modeling improvements were made to the TRNSYS/TRNSED model that CDH had previously developed for desiccant and dehumidifier systems. The model improvements, listed in Figure 1, allowed for more accurate, real-world simulation results. The short time-step model allowed precise determination of when mechanical equipment would be on or off according to actual control strategies. Referring to Figure 2, space conditioning equipment, ventilation equipment, and dehumidification equipment could all be operating at the same time, with all the heat and moisture consequences accounted for in the same simulation time interval. 


\section{Modeling Approach}

- Using TRNSYS model first developed for Desiccant and DH systems

- Uses small time step (72 sec)

- No more part load curves (either ON or OFF)

- Thermostat dynamics (for cooling)

- Detailed control of all components (e.g., CFIS)

- Type 56 for multi-zone building

- Combined duct leakage \& infiltration calcs

- Robust equipment models (performance maps)

Figure 1. Computer modeling improvements allowing more realistic simulation results.

\section{Updated Simulation Framework}

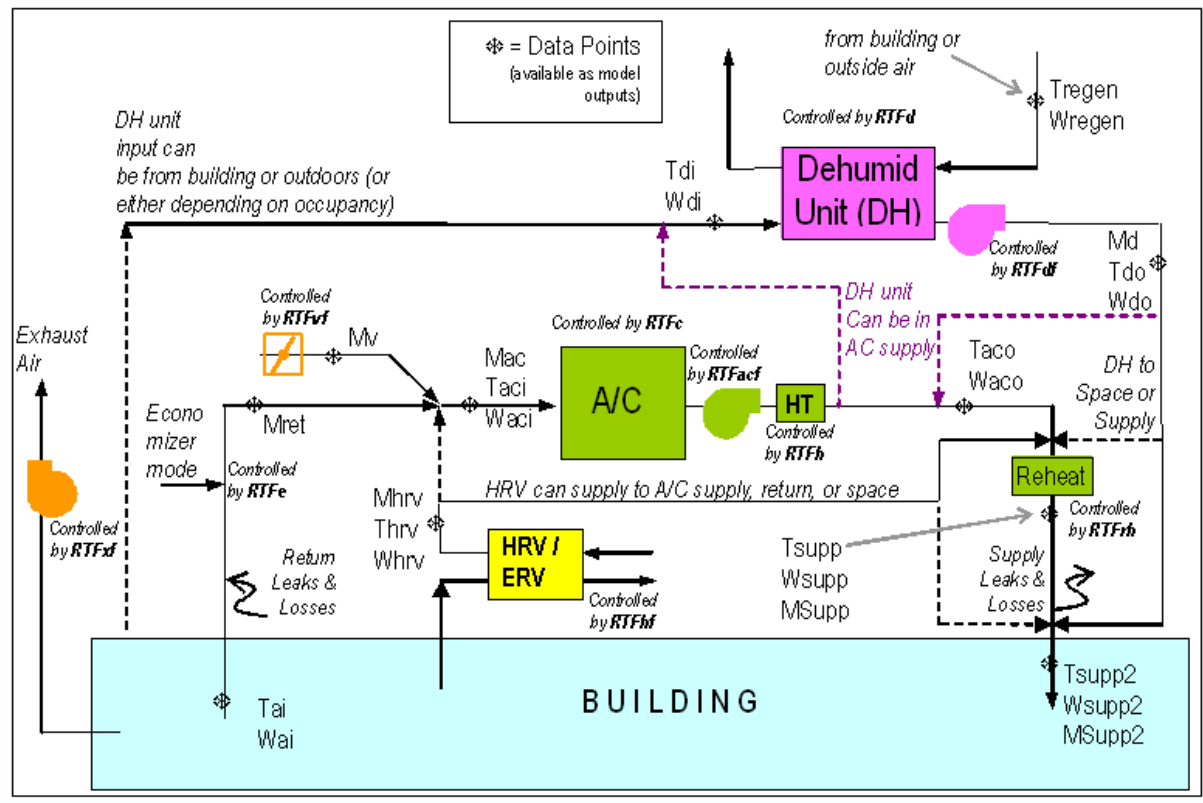

Figure 2. Simulation framework that allows for multiple temperature control, humidity control, ventilation, and fan recirculation systems to operate at the same time. 
Moisture evaporation from wet cooling coils is modeled to realistically account for cooling and dehumidification system latent degradation (moisture added back to the ducts and conditioned space) when the cooling compressor is off.

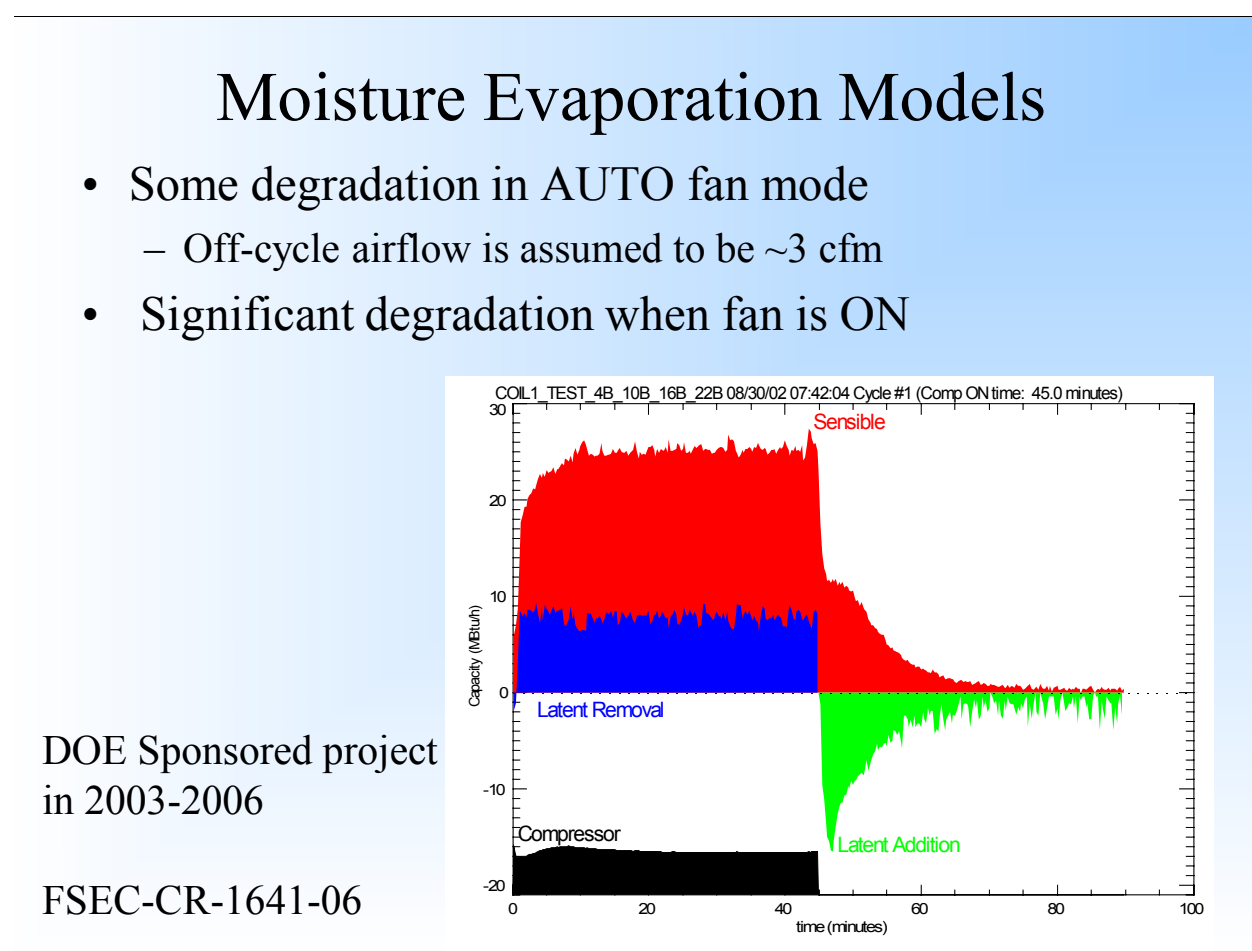

Figure 3. Simulation framework that allows for multiple temperature control, humidity control, ventilation, and fan recirculation systems to operate at the same time.

The combined airflow of infiltration, duct leakage, and balanced and unbalanced ventilation is accounted for, as shown in Figure 4.

Figure 5 illustrates the conventional cooling system and indoor temperature and RH response with heating, cooling, and floating hours in the same day. Floating hours are times when no space conditioning is active because the house remains between the heating and cooling control setpoints. For the warm-humid climate, the heating and cooling thermostat setpoints were $73^{\circ} \mathrm{F}$ and $78^{\circ} \mathrm{F}$ ). The expected space conditioning equipment operation, and the temperature and $\mathrm{RH}$ response, is shown. 


\section{Integrated Infiltration, Ventilation and Duct Leakage}

- Currently integrate infiltration and ventilation (balanced, unbalanced)

\begin{tabular}{|c|c|c|}
\hline $\mathrm{cfm}_{\text {in }}$ & $=$ & Vent inlet + return duct leaks \\
\hline $\mathrm{cfm}_{\text {out }}$ & $=$ & Exhaust + Supply duct leaks \\
\hline $\mathrm{cfm}_{\text {balanced }}$ & $=$ & $\operatorname{MIN}\left(\mathrm{cfm}_{\mathrm{in}}, \mathrm{cfm}_{\text {out }}\right)$ \\
\hline $\mathrm{cfm}_{\text {unbalanced }}$ & $=$ & $\operatorname{MAX}\left(\mathrm{cfm}_{\text {in }}, \mathrm{cfm}_{\text {out }}\right)-\mathrm{cfm}_{\text {balanced }}$ \\
\hline $\mathrm{cfm}_{\text {inf }}$ & $=$ & $\begin{array}{l}\text { infiltration flow calculated for } \\
\text { building for the timestep }\end{array}$ \\
\hline $\mathrm{cfm}_{\text {combined }}$ & $=$ & $\begin{array}{l}\operatorname{MAX}\left(\mathrm{cfm}_{\text {unbalanced }}, \mathrm{cfm}_{\mathrm{inf}}+0.5^{*} \mathrm{cfm}_{\text {unbalanced }}\right) \\
+\mathrm{cfm}_{\text {balanced }}\end{array}$ \\
\hline
\end{tabular}

Figure 4. Calculation of the combined airflow of infiltration, duct leakage, and balanced and unbalanced ventilation.

\section{Conv AC (System 1)}
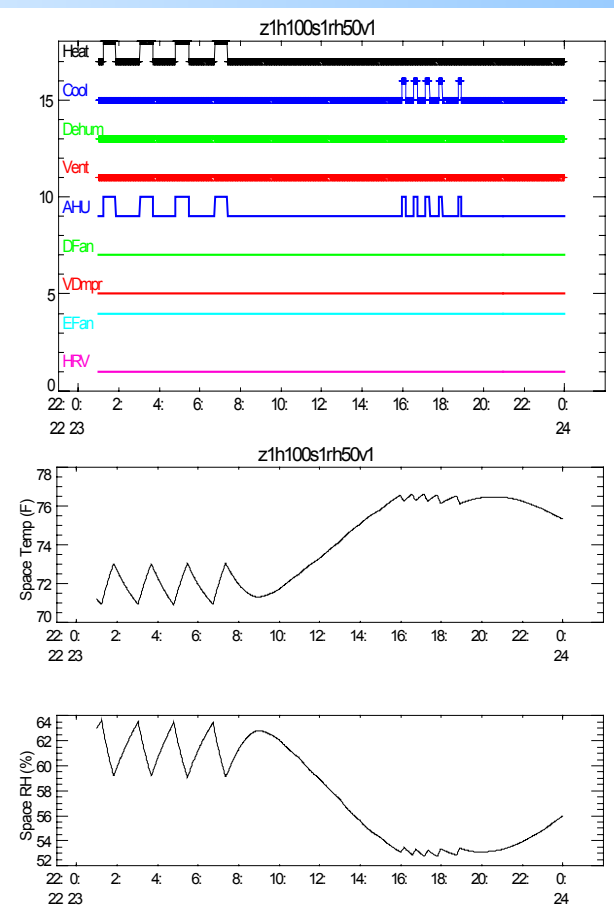

Figure 5. Conventional cooling system and indoor temperature and RH response with heating, floating, and cooling hours in the same day. 


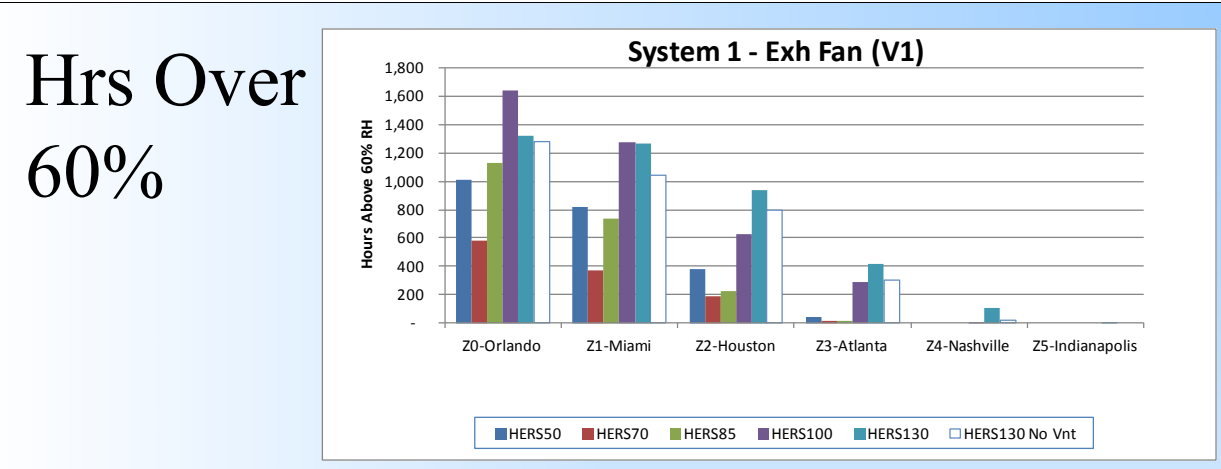

No of

$4 \mathrm{hr}$

Events

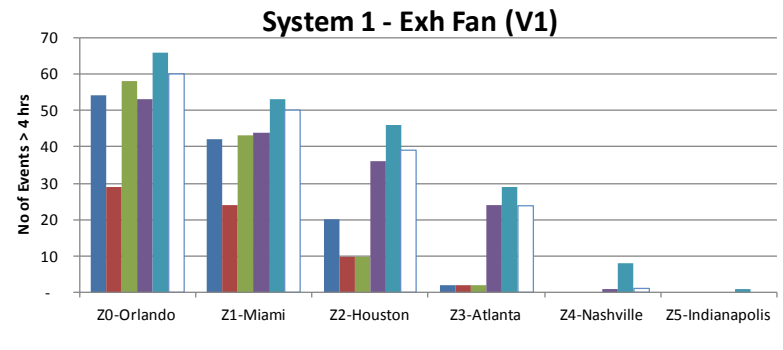

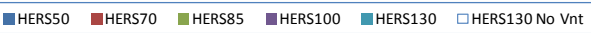

Figure 6. RH limit expressed as hours over $60 \% \mathrm{RH}$ and 4 hour events over $60 \% \mathrm{RH}$.

A number of references (ASHRAE Standard 55-2010, Balaras and Balaras 2007, Wolkoff and Kjaergaard 2007) refer to indoor RH between $30 \%$ and $60 \%$ as comfortable, healthy, and recommended for human occupancy. In Rudd and Henderson 2007, based on measured data from over 40 sites, an analysis approach was presented whereby hours over $60 \% \mathrm{RH}$ and 4 -hour events over $60 \% \mathrm{RH}$ were examined. The logic was that if many of the hours over $60 \% \mathrm{RH}$ occurred sporadically, and did not accumulate to long events, then perhaps both ways of characterizing unacceptably elevated indoor humidity would be needed. It was shown that hours over $60 \% \mathrm{RH}$ and 4-hour events over $60 \% \mathrm{RH}$ had essentially the same result profile and gave essentially the same answer. That was because most hours over $60 \% \mathrm{RH}$ did not occur sporadically, but in lumped time periods. A mostly similar comparison was found when extending the analysis to 8-hour events over $60 \%$ RH. Referring to Figure 6, the same result was found in the computer simulations presented here.

Figure 7 shows a sensitivity of ventilation rate for a house rated at a HERS Index of 70 with exhaust ventilation and no cooling system dehumidification enhancements or supplemental dehumidification. The ventilation rate was simulated at $50 \%, 100 \%$, and $150 \%$ of the ASHRAE Standard 62.2-2010 rate. Total space conditioning energy cost typically went down about 10\% when the ventilation rate was reduced by $50 \%$, and went up about $10 \%$ when the ventilation rate was increased by $50 \%$. However, for the hot-humid climates of Miami, Orlando, and Houston, the hours where indoor RH was above $60 \%$ varied much more, and sometimes in different directions. In Orlando, reducing the ventilation rate increased the hours above $60 \%$ RH by 72 hours because of less drying potential in wintertime, but increasing the ventilation rate increased the hours above $60 \%$ RH by 252 hours. In both Miami and Houston, reducing the ventilation rate 
reduced the hours above $60 \% \mathrm{RH}$ by $63 \%$ and $23 \%$, respectively, and increasing the ventilation rate increased the hours above $60 \% \mathrm{RH}$ by $76 \%$ and $35 \%$, respectively.

\section{Impact of Ventilation Rate \\ HERS70}

\begin{tabular}{|c|c|c|c|c|c|c|c|c|c|c|c|c|}
\hline & Exh Vent & $\begin{array}{r}\text { Hours } \\
\text { Above } \\
60 \% \mathrm{RH}\end{array}$ & $\begin{array}{r}\mathrm{AC} \\
\text { Runtime } \\
(\mathrm{hrs}) \\
\end{array}$ & $\begin{array}{r}\text { AC EER } \\
(B t u / W h)\end{array}$ & $\begin{array}{r}\mathrm{AC} \\
\text { Energy } \\
(\mathrm{kWh})\end{array}$ & $\begin{array}{r}\text { Htg } \\
\text { Energy } \\
(\mathrm{kWh}) \\
\end{array}$ & $\begin{array}{r}\text { AHU Fan } \\
\text { Energy } \\
\text { (kWh) }\end{array}$ & $\begin{array}{r}\text { Exh } \\
\text { Fan } \\
\text { Energy } \\
(\mathbf{k W h})\end{array}$ & $\begin{array}{r}\text { HRV } \\
\text { Energy } \\
(\mathbf{k W h})\end{array}$ & $\begin{array}{r}\text { Total } \\
\text { Electric } \\
\text { w/o HT } \\
(\mathbf{k W h}) \\
\end{array}$ & \begin{tabular}{|r|} 
Total \\
Costs w \\
Furnace \\
$(\$)$ \\
\end{tabular} & \\
\hline \multirow{3}{*}{ Orlando } & $50 \%$ Vent & 678 & 1,774 & 16.6 & 3,093 & 554 & 594 & 91 & - & 3,778 & 419 & $91 \%$ \\
\hline & $100 \%$ Vent & 606 & 1,851 & 16.7 & 3,270 & 686 & 622 & 203 & - & 4,095 & 460 & $100 \%$ \\
\hline & $150 \%$ Vent & 858 & 1,915 & 16.8 & 3,419 & 862 & 646 & 305 & - & 4,370 & 500 & $109 \%$ \\
\hline \multirow{3}{*}{ Miami } & $50 \%$ Vent & 159 & 2,981 & 16.6 & 4,181 & 25 & 783 & 91 & - & 5,055 & 512 & $93 \%$ \\
\hline & $100 \%$ Vent & 433 & 3,122 & 16.7 & 4,430 & 42 & 820 & 203 & - & 5,453 & 554 & $100 \%$ \\
\hline & $150 \%$ Vent & 763 & 3,247 & 16.7 & 4,647 & 55 & 853 & 305 & - & 5,805 & 590 & $107 \%$ \\
\hline \multirow{3}{*}{ Houston } & $50 \%$ Vent & 164 & 2,307 & \begin{tabular}{l|l|}
16.3 \\
\end{tabular} & 3,241 & 1,792 & 635 & 91 & - & 3,967 & 411 & $92 \%$ \\
\hline & $100 \%$ Vent & 214 & 2,391 & 16.4 & 3,403 & 2,045 & 661 & 203 & - & 4,267 & 446 & $100 \%$ \\
\hline & $150 \%$ Vent & 288 & 2,461 & 16.5 & 3,537 & 2,522 & 687 & 305 & - & 4,529 & 488 & $109 \%$ \\
\hline \multirow{3}{*}{ Atlanta } & $50 \%$ Vent & 27 & 1.525 & 16.5 & 2,098 & 4.126 & 468 & 91 & - & 2657 & 512 & $91 \%$ \\
\hline & $100 \%$ Vent & 15 & 1,558 & 16.6 & 2,167 & 4,612 & 485 & 203 & - & 2,855 & 560 & $100 \%$ \\
\hline & $150 \%$ Vent & 40 & 1,577 & 16.6 & 2,214 & 5,251 & 500 & 305 & - & 3,019 & 614 & $110 \%$ \\
\hline
\end{tabular}

Figure 7. Impact of exhaust ventilation rate at $50 \%, 100 \%$ and $150 \%$ of the ASHRAE Standard 62.2 2010 whole-building ventilation rate.

A sensitivity comparing a conventional cooling system in a HERS 70 level house with cooling systems modified to increase latent capacity and a 50\% RH setpoint is shown in Figure 8.

Enhanced AC represents three degrees of overcooling and lowered airflow $(210 \mathrm{cfm} /$ ton vs. 375 $\mathrm{cfm} /$ ton). This showed a reduction in hours over $60 \% \mathrm{RH}$ of about $95 \%$ in Miami, $75 \%$ in Houston, and 50\% in Orlando. However, field experience has shown that three degrees of overcooling (cooling to three degrees below the requested setpoint) causes comfort complaints. Note that the total space conditioning system operating cost is not directly comparable between the conventional system and the enhanced system because the enhanced system was modeled with a more efficient cooling system, as typically dictated in the market for systems with variable airflow.

Heat pipes (passive system for pre-cooling air entering the evaporator and reheating air leaving the evaporator) show a reduction in hours over $60 \% \mathrm{RH}$ of about $90 \%$ in Miami, $60 \%$ in Houston, and $30 \%$ in Orlando. Due to the increased static pressure and associated increase in fan energy consumption associated with the heat pipe system, the total space conditioning system energy consumption and operating cost increased by $20 \%-25 \%$. 
With an indoor RH setpoint of 50\%, the Humiditrol system by Lennox (employing overcooling by three degrees and refrigerant subcooling reheat) was able to control indoor RH below $60 \%$ in Miami and Houston, but still showed 32 hours above $60 \%$ RH in Orlando. Those hours occurred when overcooling had reached its limit.

\section{Enhanced Systems HERS70}

\begin{tabular}{|c|c|c|c|c|c|c|c|c|c|c|}
\hline & & $\begin{array}{r}\text { Hours } \\
\text { Above } \\
60 \% \mathrm{RH}\end{array}$ & $\begin{array}{r}\mathrm{AC} \\
\text { Runtime } \\
\text { (hrs) }\end{array}$ & $\begin{array}{r}\text { AC EER } \\
(\text { Btu/Wh })\end{array}$ & $\begin{array}{r}\mathrm{AC} \\
\text { Energy } \\
(\mathbf{k W h})\end{array}$ & $\begin{array}{r}\mathrm{Htg} \\
\text { Energy } \\
(\mathrm{kWh})\end{array}$ & $\begin{array}{r}\text { AHU Fan } \\
\text { Energy } \\
\text { (kWh) }\end{array}$ & $\begin{array}{r}\text { Exh Fan } \\
\text { Energy } \\
(\mathbf{k W h})\end{array}$ & $\begin{array}{r}\text { Total } \\
\text { Electric } \\
\text { w/o HT } \\
\text { (kWh) }\end{array}$ & \begin{tabular}{|r|} 
Total \\
Costs w \\
Furnace \\
(\$) \\
\end{tabular} \\
\hline \multirow{4}{*}{ Orlando } & Conv AC & 606 & 1,851 & 16.7 & \begin{tabular}{l|l}
3,270 \\
\end{tabular} & 686 & 622 & 203 & 4,095 & 460 \\
\hline & Enhanced AC & 308 & 3,826 & 20.8 & 2,756 & 699 & 196 & 203 & 3,155 & 366 \\
\hline & $\mathrm{AC} \mathrm{w/} \mathrm{HPs}$ & 418 & 2,311 & 16.0 & 3,799 & 689 & 1,126 & 203 & 5,128 & 565 \\
\hline & Lennox Humiditrol & 32 & 4,000 & 17.0 & 3,374 & 703 & 265 & 203 & 3,843 & 436 \\
\hline \multirow{4}{*}{ Miami } & Conv AC & 433 & 3,122 & 16.7 & 4,430 & 42 & 820 & 203 & 5,453 & 554 \\
\hline & Enhanced AC & 20 & 5,721 & 19.9 & 3,772 & 48 & 339 & 203 & 4,315 & 439 \\
\hline & $\mathrm{AC}$ w/ HPs & 46 & 3,846 & 16.0 & 5,064 & 42 & 1,482 & 203 & 6,749 & 685 \\
\hline & Lennox Humiditrol & - & 5,686 & 16.9 & 4,413 & 42 & 432 & 203 & 5,048 & 513 \\
\hline \multirow{4}{*}{ Houston } & ConvAC & 214 & 2,391 & 16.4 & 3,403 & 2,045 & 661 & 203 & 4,267 & 446 \\
\hline & Enhanced AC & 53 & 4,016 & 19.3 & 2,914 & 2,045 & 342 & 203 & 3,459 & 378 \\
\hline & $\mathrm{AC} \mathrm{w} / \mathrm{HPs}$ & 93 & 2,918 & 15.9 & 3,837 & 2,044 & 1,157 & 203 & 5,197 & 525 \\
\hline & Lennox Humiditrol & - & 4,061 & 17.3 & 3,233 & 2,039 & 380 & 203 & 3,817 & 408 \\
\hline \multirow{4}{*}{ Atlanta } & Conv AC & 15 & 1,558 & 16.6 & \begin{tabular}{l|l|}
2,167 \\
\end{tabular} & 4,612 & 485 & 203 & 2,855 & 560 \\
\hline & Enhanced AC & 15 & 2,619 & 19.7 & 1,819 & 4,594 & 270 & 203 & 2,292 & 501 \\
\hline & $\mathrm{AC} \mathrm{w} / \mathrm{HPs}$ & & & & & & & & & \\
\hline & Lennox Humiditrol & - & 2,662 & 19.2 & 1,879 & 4,595 & 274 & 203 & 2,356 & 508 \\
\hline
\end{tabular}

Figure 8. Simulation results for enhanced Systems modeled in HERS 70 level houses. 


\section{Turn off capacitance, Check Gains}

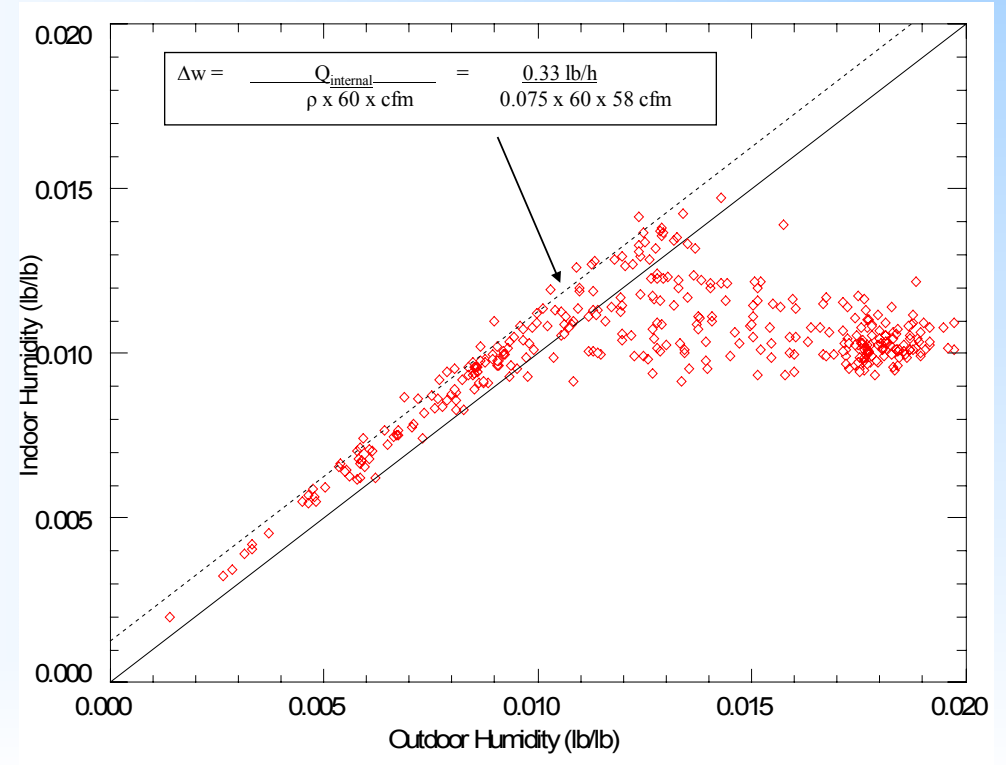

Figure 9. A check of the simulation response with moisture capacitance turned off (set to zero).

Figure 9 provides a graphical check of the expected moisture modeling result with moisture capacitance turned off (set to zero). All values to the right of the solid line represent hours where moisture was being removed from the indoor air by the cooling system. All values between the dotted and solid lines represent hours where cooling was not active and internal moisture generation pushed the indoor humidity up beyond the outdoor humidity. If there was only ventilation and no internal moisture generation, the values would follow the solid line. Values to the left of the dotted line would be indicative of moisture capacitance, as shown in Figure 10 with measured and simulated indoor vs. outdoor humidity trends with indoor moisture capacitance.

A graphic illustration of the impact of overcooling is shown in Figure 11. Comparing the two plots, one can see how overcooling by three degrees moves or "sweeps" the higher RH hours down and to the left. 


\section{Comparing Humidity Trends}
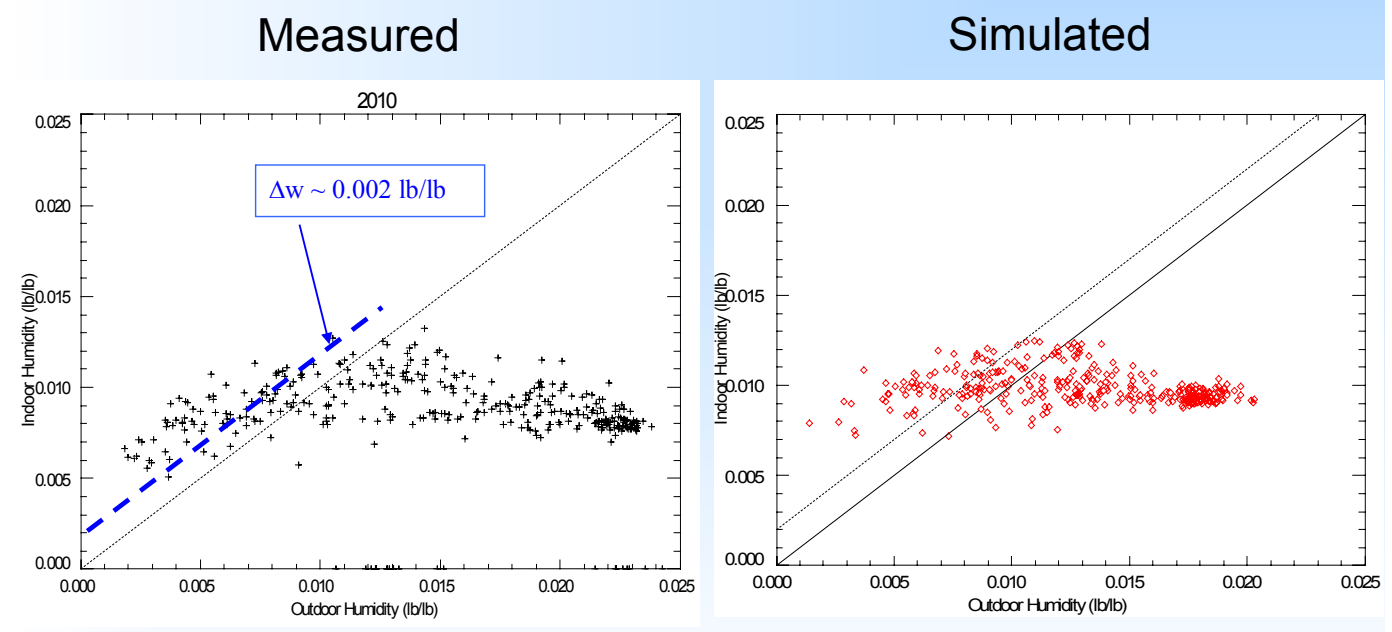

Figure 10. Measured and simulated indoor vs. outdoor humidity trends with indoor moisture capacitance.
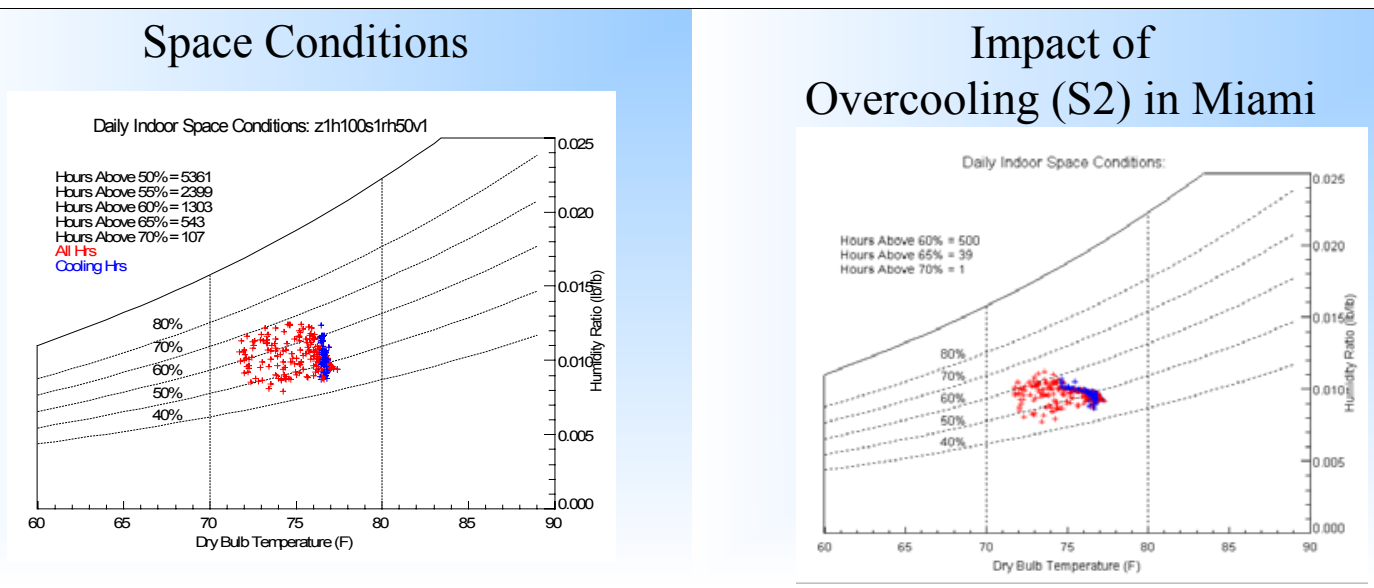

Figure 11. The impact of overcooling by three degrees "sweeps" the higher RH hours down and to the left.

Locating the air distribution system ducts inside conditioned space saves energy overall, but, with the reduced sensible cooling load, also comes an increased need for supplemental dehumidification. This impact is illustrated in Figure 12, where ducts in the attic were modeled 
with 5\% leakage (60\% supply side, 40\% return side). For the HERS 70 and HERS 50 efficiency levels, moving the ducts inside conditioned space increases the hours above $60 \% \mathrm{RH}$ indoors by $25 \%-50 \%$. A point of discussion in the meeting was that this difference may not be so large if the model were to account for the moisture desorption from wood framing materials that typically increase the attic humidity ratio over that of the outdoors during the late morning to early afternoon hours in warm-humid climates. In that case, return duct leakage would increase the moisture source for the ducts-in-attic configuration. This will be addressed in a simplified way by running an additional sensitivity with the attic dewpoint temperature being forced to $10^{\circ} \mathrm{F}$ over outdoors from 10 am to $1 \mathrm{pm}$ between May 15 and October 15. However, this may not change the result that much since examining Figure 13 shows that, in Miami, for example, most elevated indoor RH hours occur in night and morning hours between late November and March. Some nighttime and rainy periods during mild summer conditions also produce elevated indoor RH.

\section{Location of Ducts}

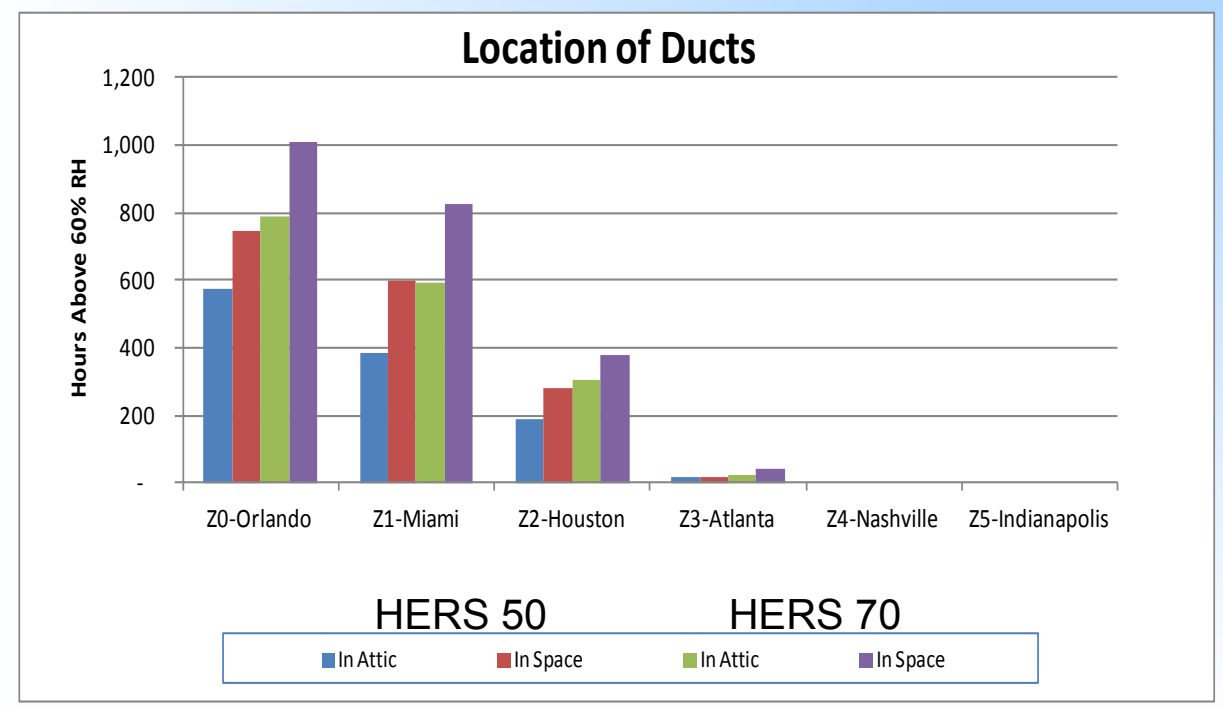

Figure 12. Locating the air distribution system ducts inside conditioned space saves overall energy, but also increases the need for supplemental dehumidification. 


\section{Shade Plot of Humidity Bins}

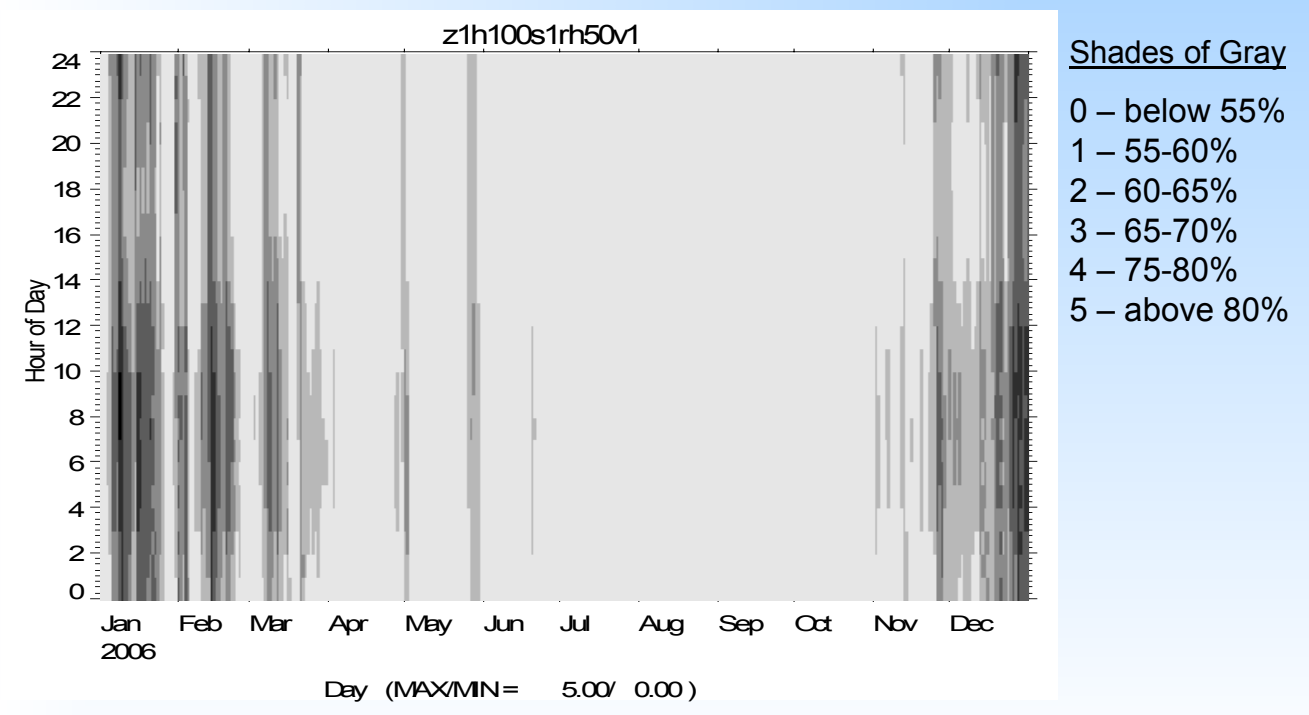

Figure 13. In Miami, hours of elevated indoor humidity occur mostly in morning hours between late November and March.

As shown in Figure 14, internal moisture generation (latent gain) and internal heat generation (sensible gain) strongly impact the predicted hours of elevated indoor humidity. Moisture generation of $12 \mathrm{lb} /$ day produces indoor humidity results that seem to fit reasonably well with monitored data for three to four bedroom dwellings. More than twice that is a worst case peak design value suggested by ASHRAE Standard 160. While that may be useful for sizing considerations in extreme cases, it is not useful for annual simulation of indoor humidity and supplemental dehumidification energy consumption. Internal sensible heat generation of 21 $\mathrm{kWh} /$ day is typical for older homes with less efficient lighting and appliances, while $15 \mathrm{kWh} /$ day is more typical of high performance homes with compact fluorescent or LED lighting and ENERGY STAR ${ }^{\circledR}$ rated appliances. Similar to ducts in hot attics, very high internal sensible heat gain drives the cooling system to operate more often and for longer runtimes, reducing indoor humidity.

Moisture capacitance does smooth hourly fluctuations in indoor humidity but it turns out that it has a relatively weak impact on hours of elevated indoor humidity (Figure 15). In Figure 15, the $15 x, 30 x$, and $45 x$ designations refer to internal moisture mass of 15, 30, and 45 times the moisture mass held in the house air volume alone. Moisture capacitance has its greatest impact when the cooling system is operating enough to intermittently drive a significant difference in indoor humidity, but that is not when most hours of elevated indoor humidity occur. Most of those hours occur when the space is floating between the cooling and heating setpoints. In that case, referring to Figure 16, raising the heating setpoint has a significant impact on reducing 
indoor RH (even though it does nothing to reduce the absolute humidity) because it keeps the air from getting as cold, stopping the rise in $\mathrm{RH}$.

\section{Moisture \& Sensible Gains}

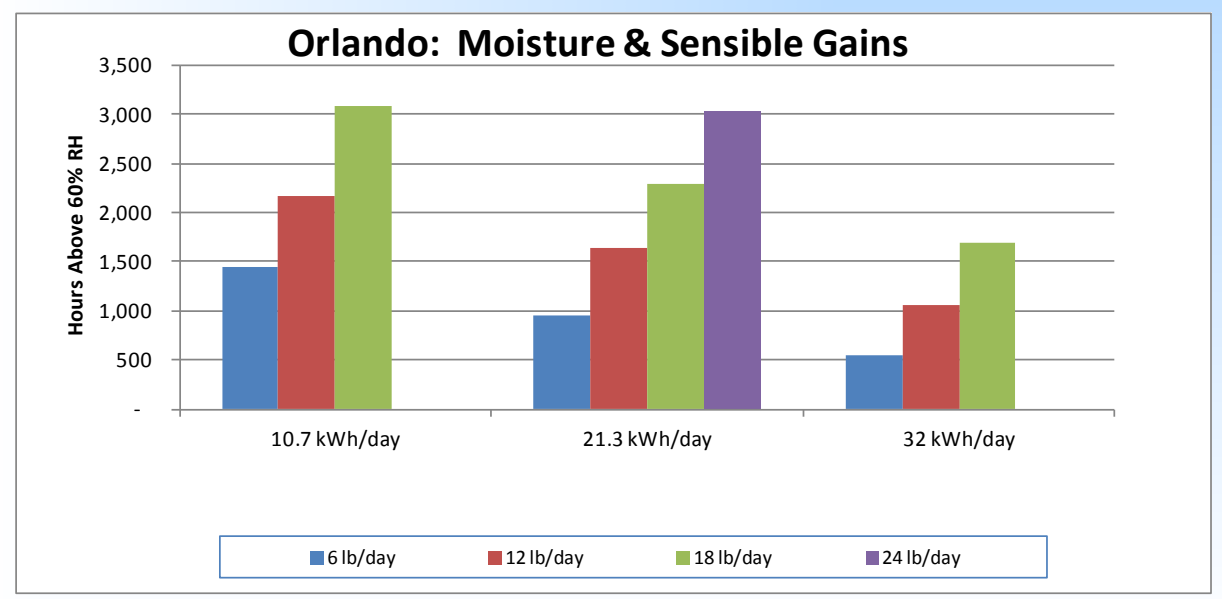

Figure 14. Hours of elevated indoor humidity is strongly related to internal moisture gains and internal sensible gains.

\section{Moisture Gains \& Capacitance}

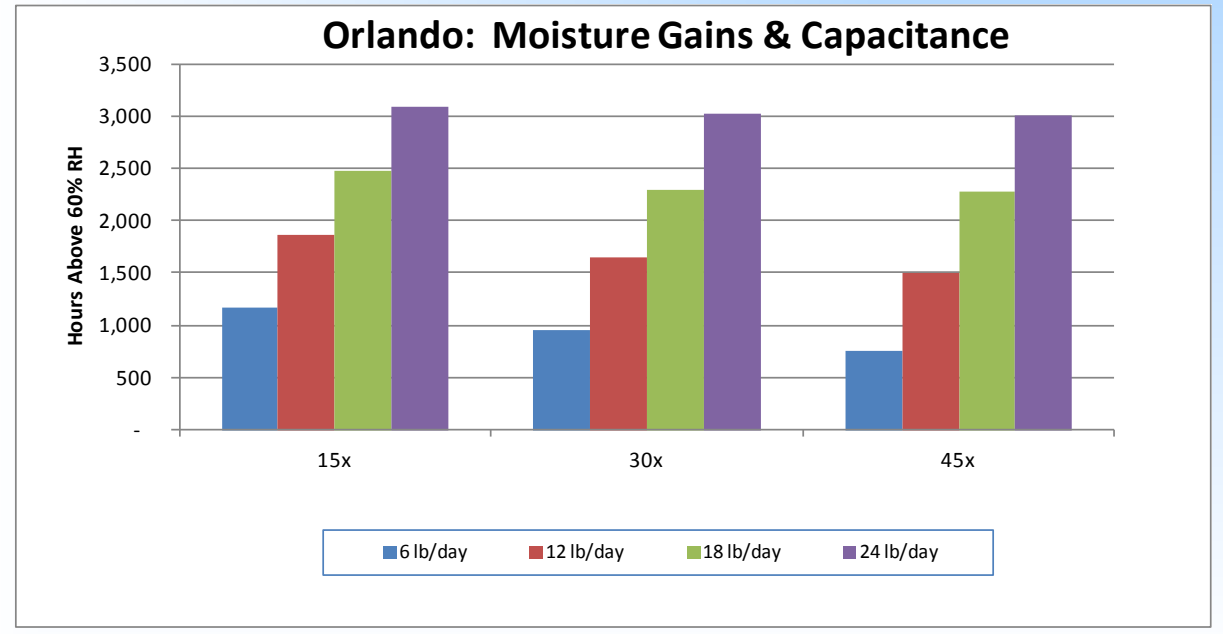

Figure 15. Hours of elevated indoor humidity is weakly related to moisture capacitance. 


\section{Sensible \& Heating Set Pts}

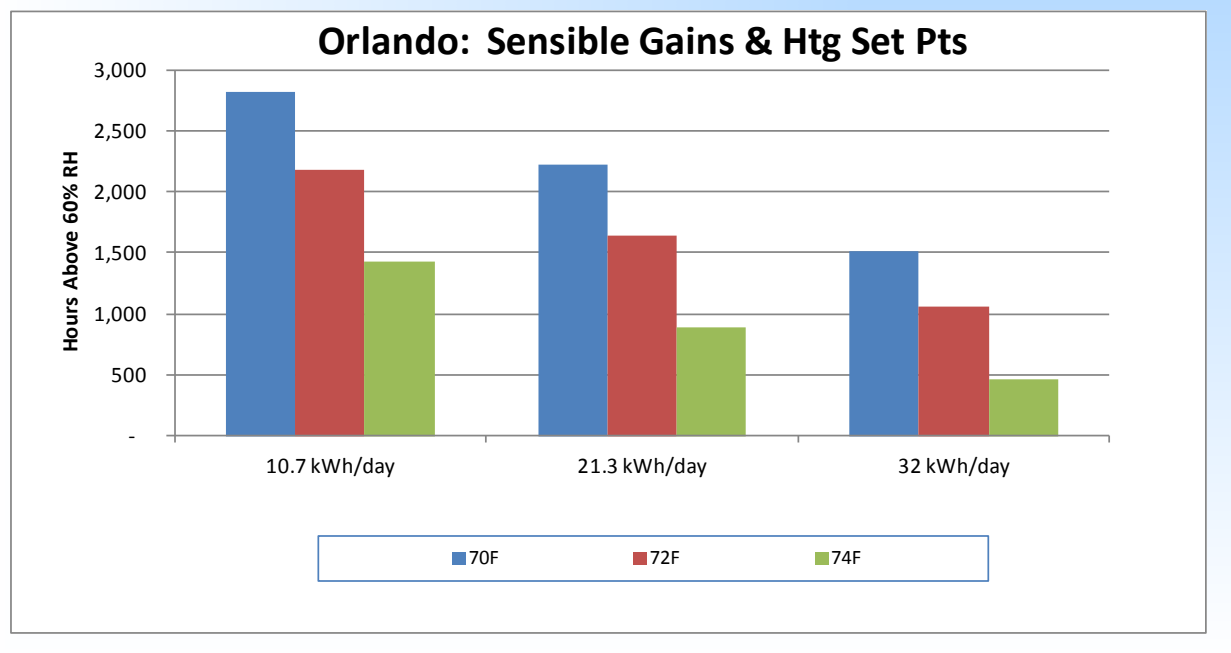

Figure 16. Hours of elevated indoor humidity is strongly related to heating setpoint.

Figure 17 shows how these data are being made available on the Internet via an interactive web application where the user can choose simulation inputs and outputs to suit a particular interest.

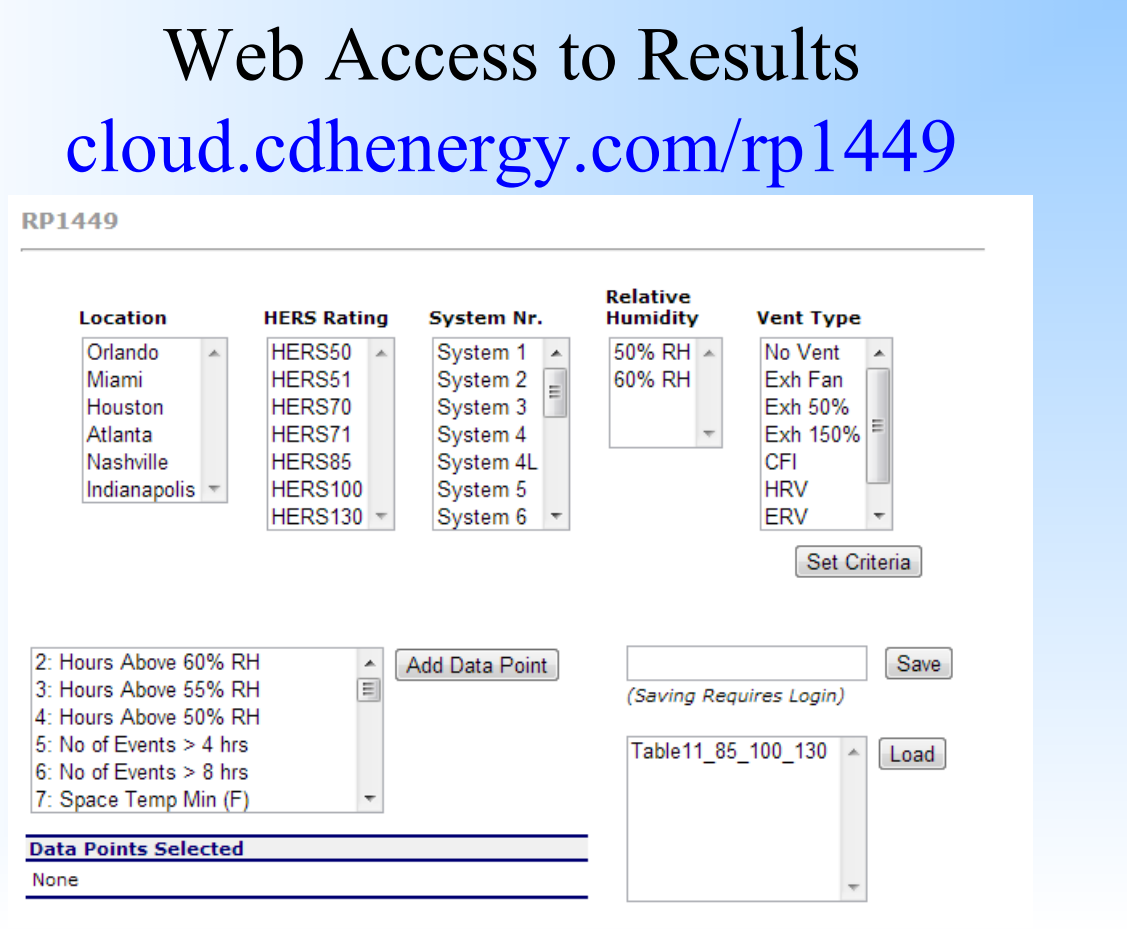

Figure 17. Interactive Internet access is made available to retrieve customized sets of the simulation data. 


\section{Humidity Control and Ventilation}

(Philip Fairey, Florida Solar Energy Center)

For a Building America ventilation white paper study with an important focus on indoor humidity impacts, twelve U.S. cities and five climate zones (Figure 18) were simulated using a customized version of the FSEC EnergyGauge USA (V3.0.01P) computer program, based on the DOE2 hourly simulation engine. Some of the custom routines were designed to improve the modeling of indoor humidity while using the temperature-only control capability of DOE2. Lumped moisture capacitance was modeled as 10 times the air mass capacitance. Latent degradation due to evaporation of moisture from wet cooling coils during cooling system off cycles was not modeled.

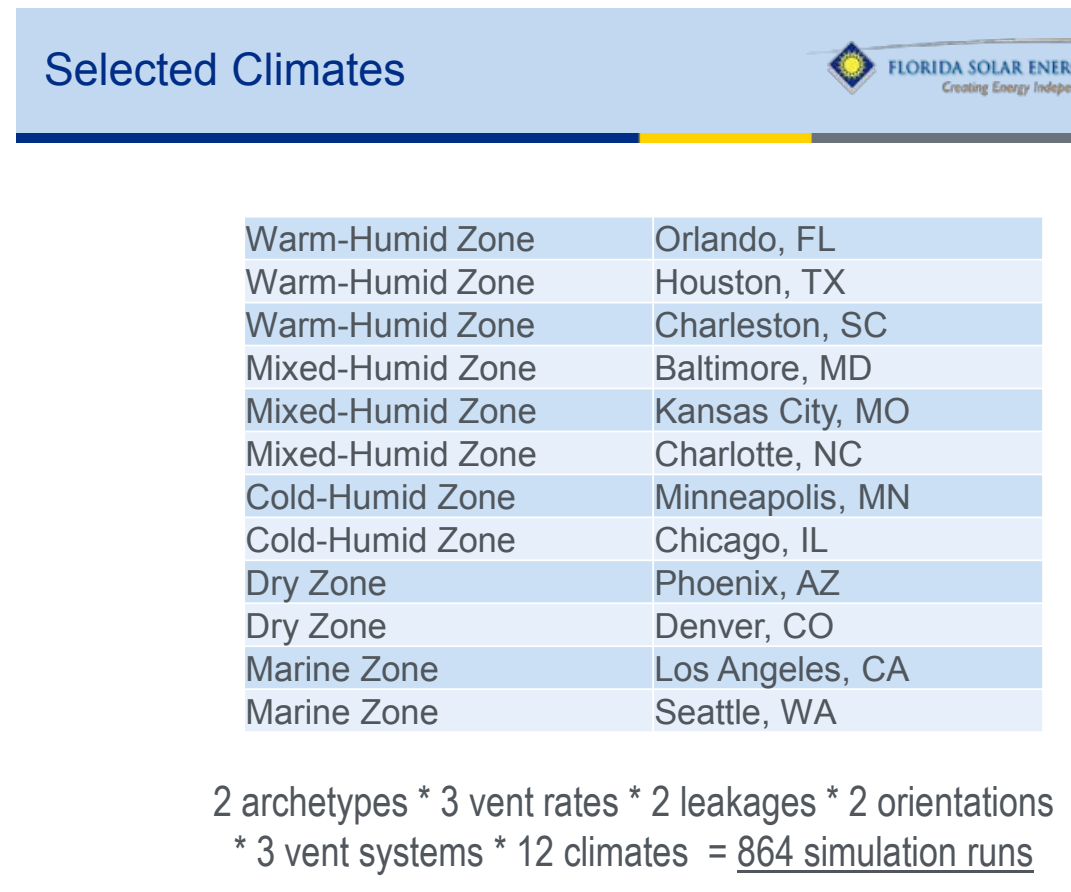

7 | Building America Partnership for Improved Residential Construction

ba-pirc.org

Figure 18. Twelve cities and five climate zones simulated for a ventilation study including humidity impacts.

A detailed set of simulation prototype assumptions were laid down to facilitate identical inputs for the FSEC and IBACOS simulations. Figure 19 lists many of those assumptions. The HERS Index of the configured home (which varied some by climate) was in the mid to upper 50's, falling between the HERS 50 and HERS 70 homes of the $\mathrm{CDH}$ simulations. The heating and cooling thermostat setpoints were shifted 2 degrees lower for the FSEC and IBACOS simulations $\left(71^{\circ} \mathrm{F}\right.$ and $\left.76^{\circ} \mathrm{F}\right)$ which would tend to decrease the hours above $60 \% \mathrm{RH}$ at the edge of cooling demand and increase the hours above $60 \% \mathrm{RH}$ at the edge of heating demand. 
- Two home archetypes:

- $2000 \mathrm{ft}^{2}$, 1-story, 3-bedroom, slab-on-grade, frame

- $2400 \mathrm{ft}^{2}$, 2-story, 3-bedroom, slab-on-grade, frame

- Both homes:

- $15 \%$ window-floor-area ratio

- DOE Challenge Home qualification

- HERS Index: mid to upper 50s

- Duct system and AHU located in conditioned space with zero leakage

- Thermostat set points: heating $=71 \mathrm{~F} ;$ cooling $=76 \mathrm{~F}$

- Mechanical ventilation is continuous (every hour)

- Window opening for natural ventilation is not allowed

\section{Other Archetype Assumptions}

- Two enclosure leakage rates:

- 3 ach50 (tight)

- 1.5 ach50 (very tight)

- Best case and worst case window orientations

- Best case window area distribution:

- N \& S window area $=35 \%$ of total

- $E \& W$ window area $=15 \%$ of total

- Worst case is rotated $90^{\circ}$

- 16 " roof overhang on all sides of hip roof with vented attic

- Infiltration heights (requires modification of DOE-2)

- 1-story $=9$ feet

- 2-story $=17.5$ feet

Figure 19. Outline of simulation prototype assumptions.

Internal moisture and sensible heat gains were modeled according to the magnitude and schedule provided in Figure 20. The daily total sensible gain $(16.9 \mathrm{kWh})$ was $20 \%$ less than that used in the CDH Energy simulations $(21.3 \mathrm{kWh} /$ day), which, according to Figure 14, would tend to increase hours above $60 \%$ RH by about $8 \%$. The latent gains of $12 \mathrm{lb} /$ day were the same for both. 


\section{Internal Gains Schedule

57,717 Btu sensible gains $+12,698$ Btu (12.09 lb) latent gains

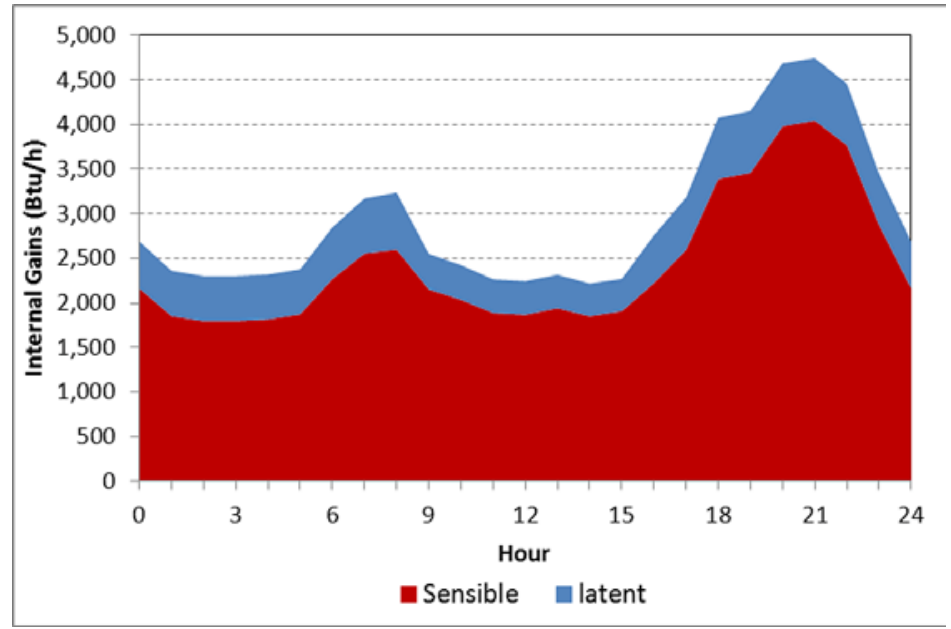

9 | Building America Partnership for Improved Residential Construction

Figure 20. Internal sensible (16.9 kWh/day) and latent gains schedule used in the simulations.

Figure 22 shows analysis of simulation results for exhaust and ERV ventilation in Orlando. The hours above $60 \% \mathrm{RH}$ are hours where the $\mathrm{RH}$ was above $60 \%$. They are distinguished by heating, cooling, and floating hours. A heating hour was where any heating occurred during that hour, a cooling hour was where any cooling occurred during that hour, and a floating hour was an hour where no heating or cooling occurred during that hour. In an hour where both heating and cooling occurred, the one with the greater runtime was designated. The simulation assumed that the windows were closed and the space conditioning system was used all year.

As shown in Figure 22, most of the hours significantly above $60 \%$ RH occur during floating hours, which occur during fall, winter, and spring in Orlando. The ERV nearly eliminated the cooling hours above $60 \% \mathrm{RH}$, but it had little effect on the floating hours above $60 \% \mathrm{RH}$. That is because the cooling system forces a greater absolute humidity difference between the indoors and outdoors, which makes the ERV transfer more moisture to the exhaust stream. However, even though the ERV was modeled with a constant $60 \%$ effectiveness, meaning that $60 \%$ of the moisture from the higher absolute humidity side would be transferred to the lower absolute humidity side, $60 \%$ of a small absolute humidity difference is still a small amount of moisture. In other words, the ERV is ineffective in keeping indoor RH down during floating hours when the difference between indoor and outdoor absolute humidity is small. 


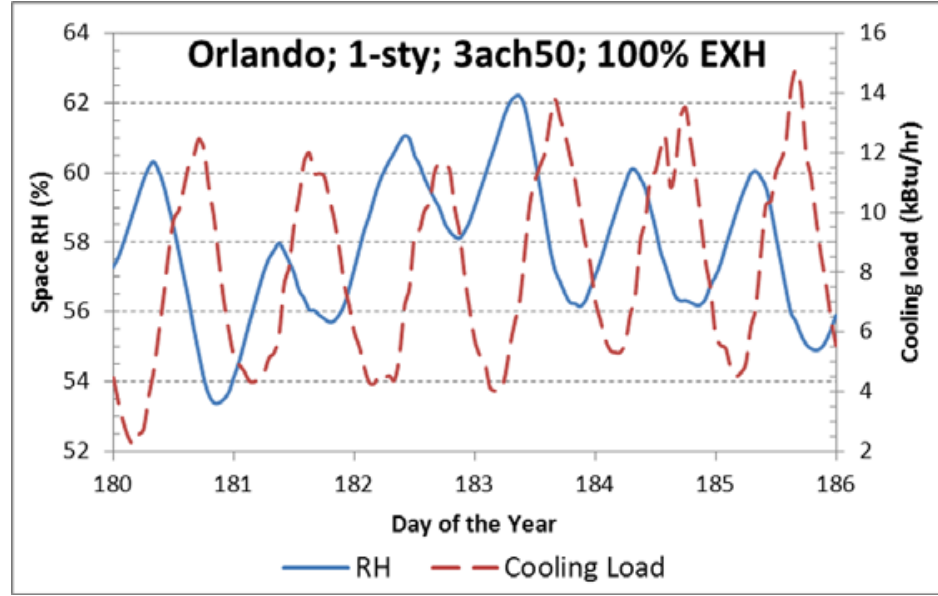

Figure 21. For a week at the end of June and beginning of July on Orlando, the cooling system and space $\mathrm{RH}$ is showing an expected response.
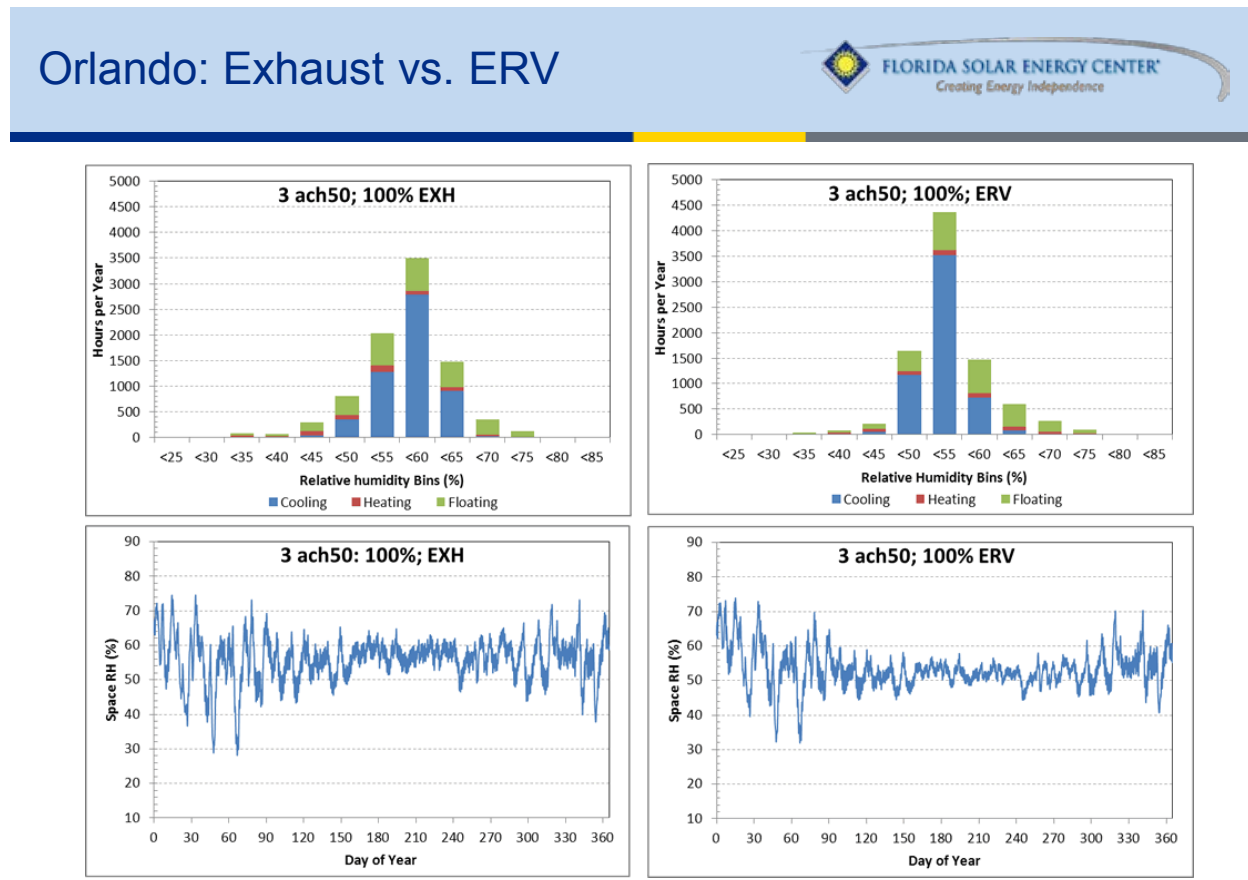

14 | Building America Partnership for Improved Residential Construction

ba-pirc.org

Figure 22. Hours above $60 \%$ RH for exhaust and ERV ventilation in Orlando. 


\section{Seasonal Impacts

HVAC condition for hours above $60 \%$ is strong function of climate

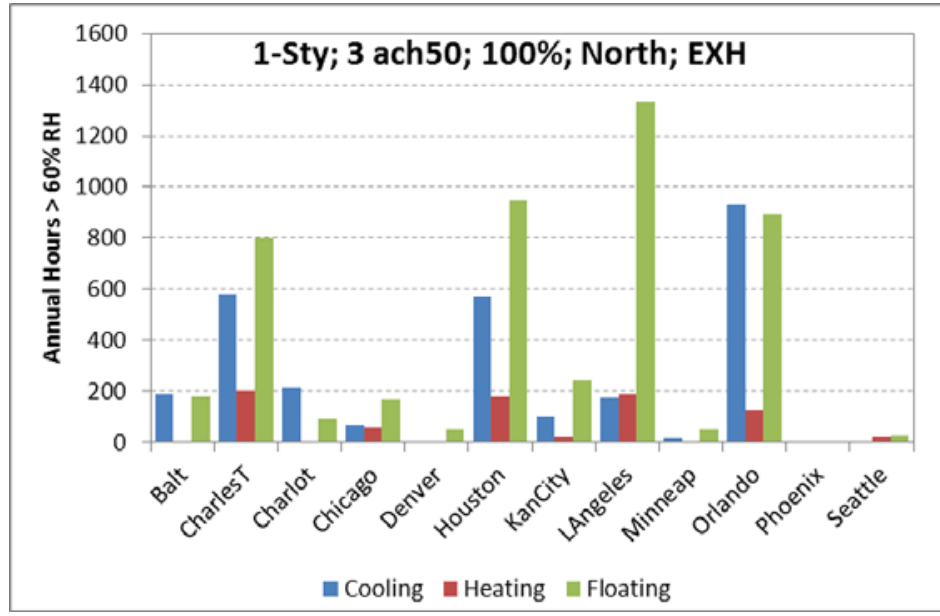

Figure 23. Hours above $60 \%$ by climate and space conditioning mode.

The hours above $60 \% \mathrm{RH}$ during a particular space conditioning mode (heating, cooling, floating) was a strong function of climate. Figure 23 shows that the hours above $60 \% \mathrm{RH}$ during heating are below 200 in every climate, but the hours above $60 \% \mathrm{RH}$ while floating can be equal to or significantly greater than the hours above $60 \% \mathrm{RH}$ during cooling and that is very dependent on the climate. For example, in Orlando, the hours above $60 \% \mathrm{RH}$ are nearly equal between cooling hours and floating hours, but in Charleston and Houston, the hours above 60\% $\mathrm{RH}$ are $35 \%$ to $50 \%$ greater for floating hours. However, the cooling hours above $60 \% \mathrm{RH}$ are generally less than $65 \% \mathrm{RH}$ while, in the warm-humid climates, the floating hours above $60 \%$ $\mathrm{RH}$ are generally in the range of $65 \%$ to $75 \% \mathrm{RH}$.

Figure 24 shows that, the hours of elevated indoor $\mathrm{RH}$ is a strong function of the selected $\mathrm{RH}$ limit and climate. For example, in Los Angeles, nearly all of the hours above $60 \% \mathrm{RH}$ are also below 65\% RH, but that is not true for Charleston, Houston, and Orlando.

Referring to Figure 25, mechanical ventilation, operated at the ASHRAE 62.2-2010 addendum $r$ rate, in a 3 ach 50 house, raises the annual median indoor RH by almost $10 \%$ RH compared to a 7 ach50 house without mechanical ventilation in Orlando. That is because infiltration drivers are generally weak in that climate during floating hours (when it is still humid outside and the cooling system is not removing moisture), but mechanical ventilation forces a minimum air exchange. Note that most of the RH increase due to ventilation is between $60 \%-65 \% \mathrm{RH}$; the hours between $65 \%-75 \%$ RH mostly remain the same. This indicates that some supplemental dehumidification would be needed in either case anyway. 
Climate Severity is a function of selected $\mathrm{RH}$ limit

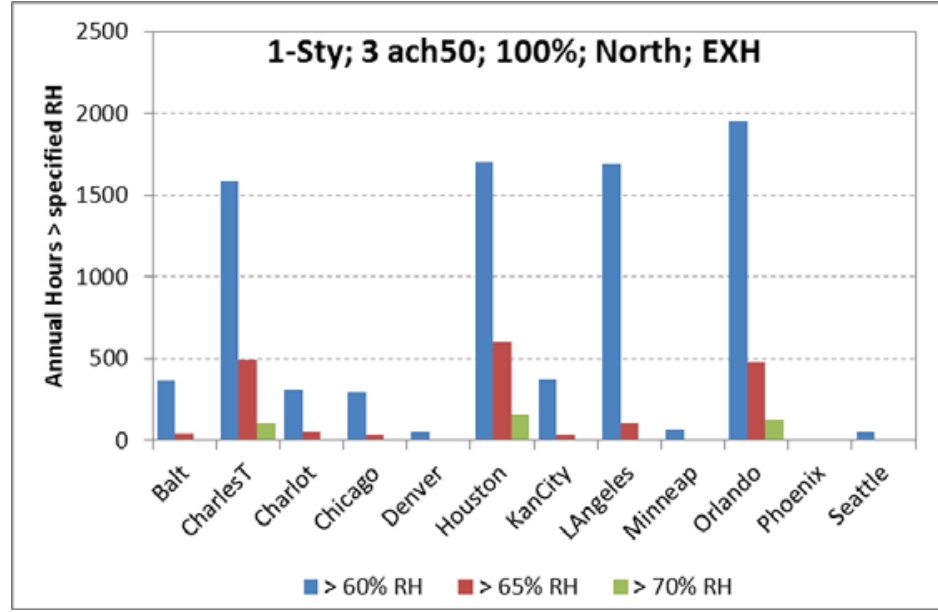

Figure 24. Hours of elevated indoor RH is a strong function of the selected RH limit and climate.

2009 IECC Envelope Leakage FLORIDA SOLAR ENERGY CENTER

ASHRAE 62.2 exhaust ventilation raises median $\mathrm{RH}$ almost $10 \%$

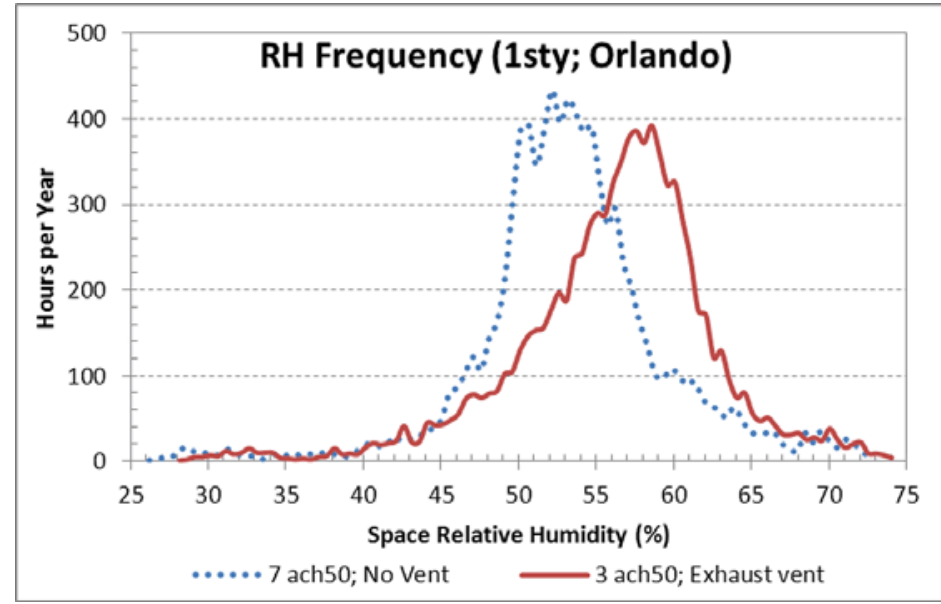

Internal gains: 57,717 Btu/day + 12.09 lb H2O/day

Figure 25. ASHRAE 62.2-2010 addendum $r$ ventilation rate raises median $\mathrm{RH}$ compared to conventional dwelling without mechanical ventilation. 


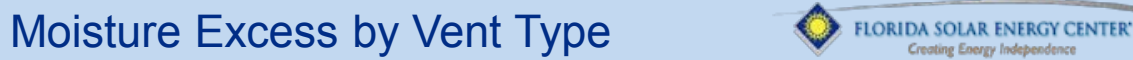

ERV systems significantly reduce moisture excess at $60 \% \mathrm{RH}$ limit

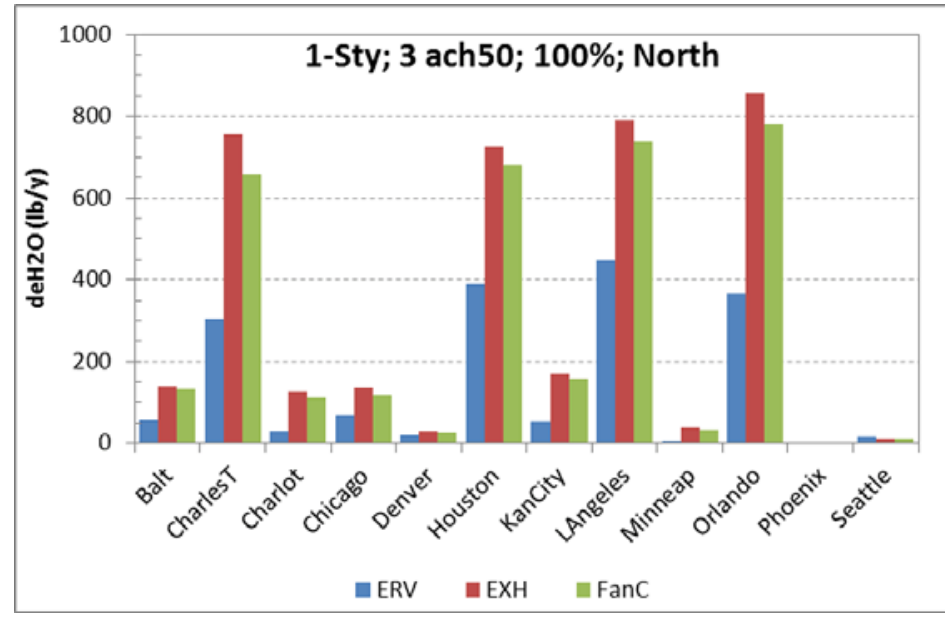

Figure 26. Predicted required moisture removal by supplemental dehumidification, by ventilation system type (energy recovery ventilator, exhaust, CFI supply).

Shown in Figure 26, removal of indoor moisture by supplemental dehumidification was approximated by the FSEC simulations by a post-processing routine that assumed that during hours over a RH limit, the net moisture gain during that hour due to air exchange and internal moisture generation would have to be removed. That strategy is only an approximation because the heat and mass transfer interactions that a real-time dehumidifier would have on the space conditions and the cooling system are not accounted for. For example, while a dehumidifier is operating, it is removing moisture and adding heat to the space, both of which drive the $\mathrm{RH}$ down. Additionally, heat added from the dehumidifier may raise the space temperature enough to cause the cooling system to come on, which then will also remove moisture. Those interactions are not accounted for in the FSEC model, but are accounted for in the CDH model.

The predicted lb/y values shown in Figure 26 are converted to $\$ / y$ in Figure 27 by an assumed dehumidifier Energy Factor of $1.47 \mathrm{~L} / \mathrm{kWh}$ and $\$ 0.12 / \mathrm{kWh}$. Based on that, supplemental dehumidification was predicted to be between $\$ 10$ and $\$ 30 / y r$ for the warm-humid climates of Charleston, Houston, and Orlando, and the marine climate of Los Angeles. 
Theoretical costs could be a factor of 2 low with poor field performance

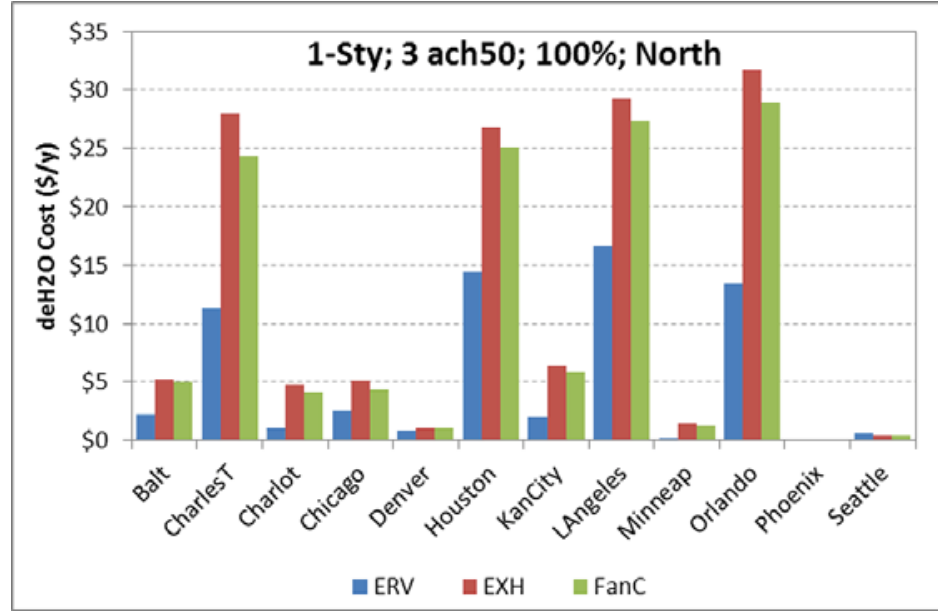

deH2O EF = 1.47 L/kWh; electricity $=\$ 0.12 / \mathrm{kWh}$

Figure 27. Predicted cost of supplemental dehumidification. 


\section{EnergyPlus Humidity Control and Ventilation Modeling Analysis}

(Michael Sypolt and Duncan Prahl, IBACOS)

IBACOS ran simulations in EnergyPlus that are parallel to those that FSEC ran in the customized version of EnergyGaugeUSA. The NREL BEopt E+ program was used to generate the geometry and base IDF files. A custom script modified parameters for about 860 runs which could be run overnight.

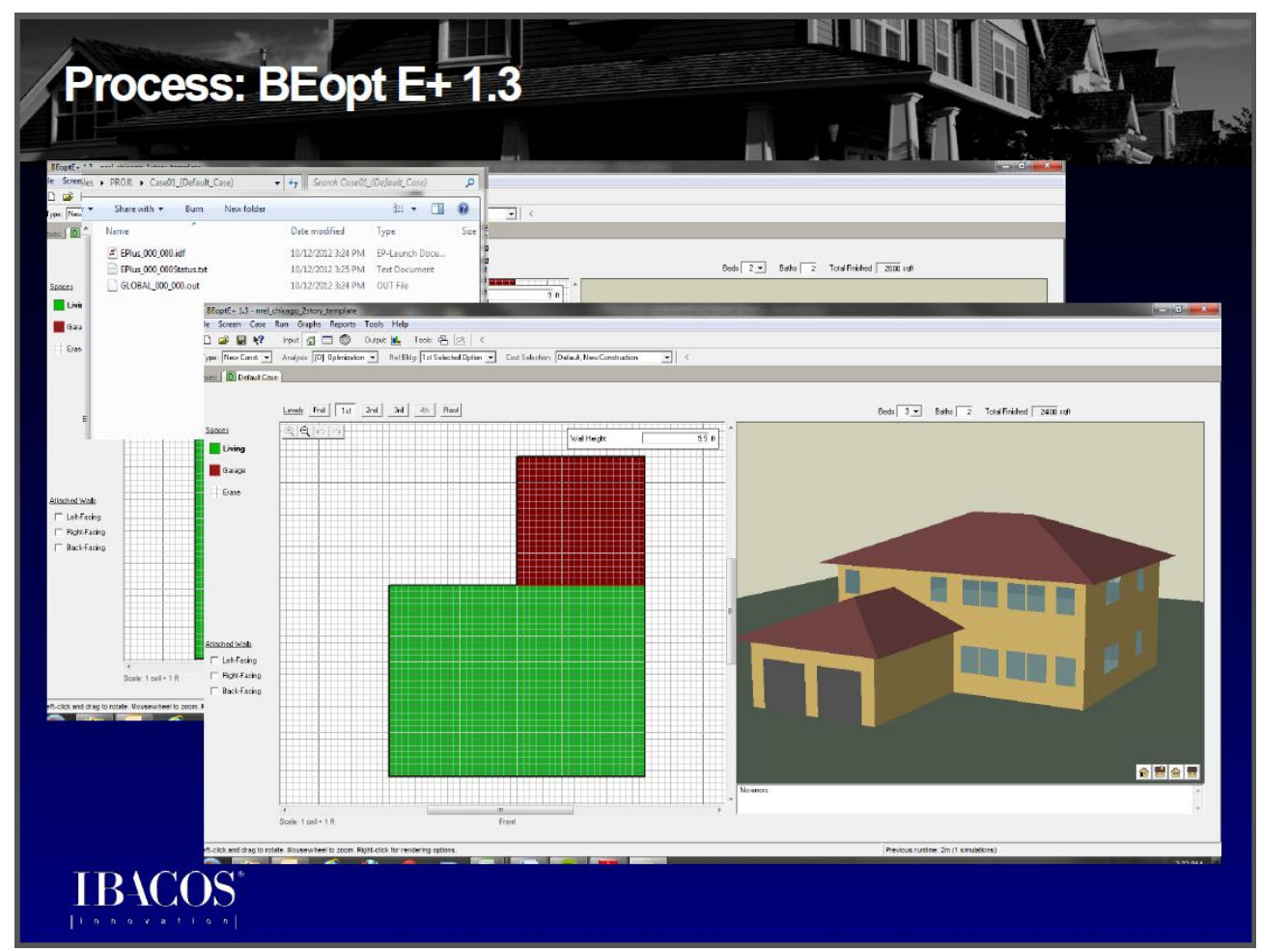

Figure 28. NREL BEopt E+ program used to generate the building geometry and the base IDF files (input description).

The model results were compared to the FSEC model results, and some input differences were corrected. Some result differences still exist. The EnergyPlus results generally show a greater number of hours over $60 \%$ RH indoors, and hours that extend to higher RH, compared to the FSEC (see Figure 29) and CDH simulations, and compared to much of BSC field data (Rudd et al. 2003, BSC 2004, Rudd et al. 2005). These might be due to differences in the infiltration model, or the infiltration-ventilation superposition. There may also be differences in the thermal energy balance model, which could lead to different loads, as another possibility. The EnergyPlus moisture modeling inputs were double checked by IBACOS and re-checked by FSEC without finding any significant discrepancies. The lumped moisture capacitance factor and moisture generation rate were consistent with the FSEC and CDH inputs. 


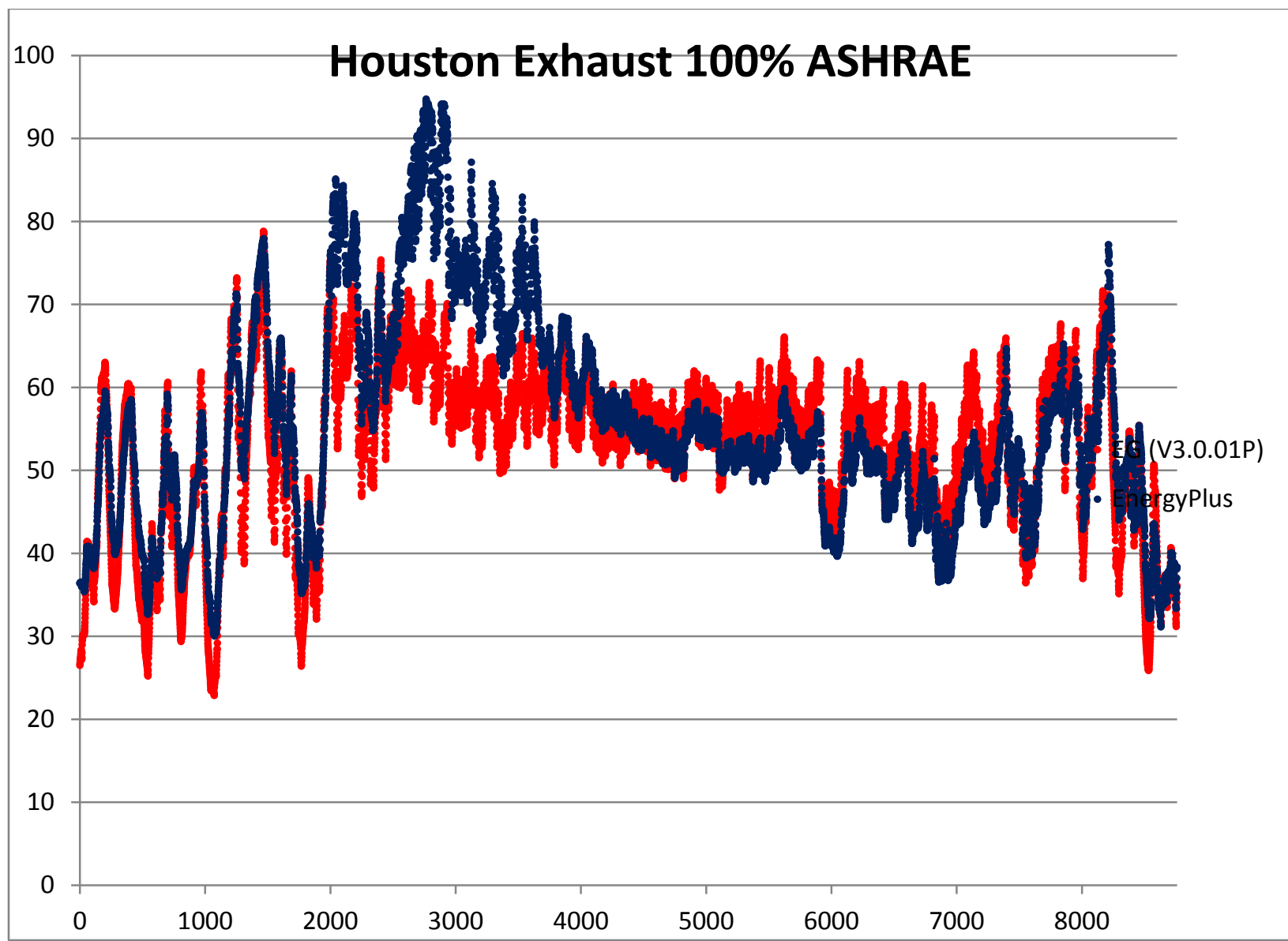

Figure 29. Indoor RH vs. hour of year comparison between EnergyPlusPlus (blue symbols) and EnergyGauge USA (V3.0.01P) simulation results.

Figure 30, shows the energy consumption results by ventilation system type, ventilation rate, and building enclosure tightness. EnergyPlus shows the differences to be relatively small in each case.

Referring to Figure 31, using the IBACOS EnergyPlus model, an ERV (not integrated with the central AHU) reduces the number of hours with lowest and highest indoor RH in Orlando. Overall, there is a reduction in indoor $\mathrm{RH}$, and a very large reduction in hours above $60 \% \mathrm{RH}$ compared to the FSEC (not integrated with the central AHU) and CDH (integrated with the central AHU) models. This result is suspect, but the cause is unclear. In each case, the ERV moisture performance was modeled pretty simply as a constant effectiveness value applied to the actual indoor to outdoor humidity ratio difference. Of the three, the $\mathrm{CDH}$ model shows the highest hours above $60 \%$ RH because the ERV was configured as being connected between the return and supply of the central AHU, as most ERVs are installed. That installation configuration requires the AHU fan to operate coincident with the ERV fan (in this case a 50\% duty cycle), which increased energy consumption and moisture evaporation when the cooling coil was wet. The $\mathrm{CDH}$ model calculates the amount of water retained on the cooling coil as a function of cooling runtime. Then, it calculates coil moisture evaporation starting each time the compressor 
stops, and when the fan runs without the compressor. The FSEC and IBACOS models configured the ERV as separately ducted from the central air distribution system, and did not model coil moisture evaporation when the compressor was off.

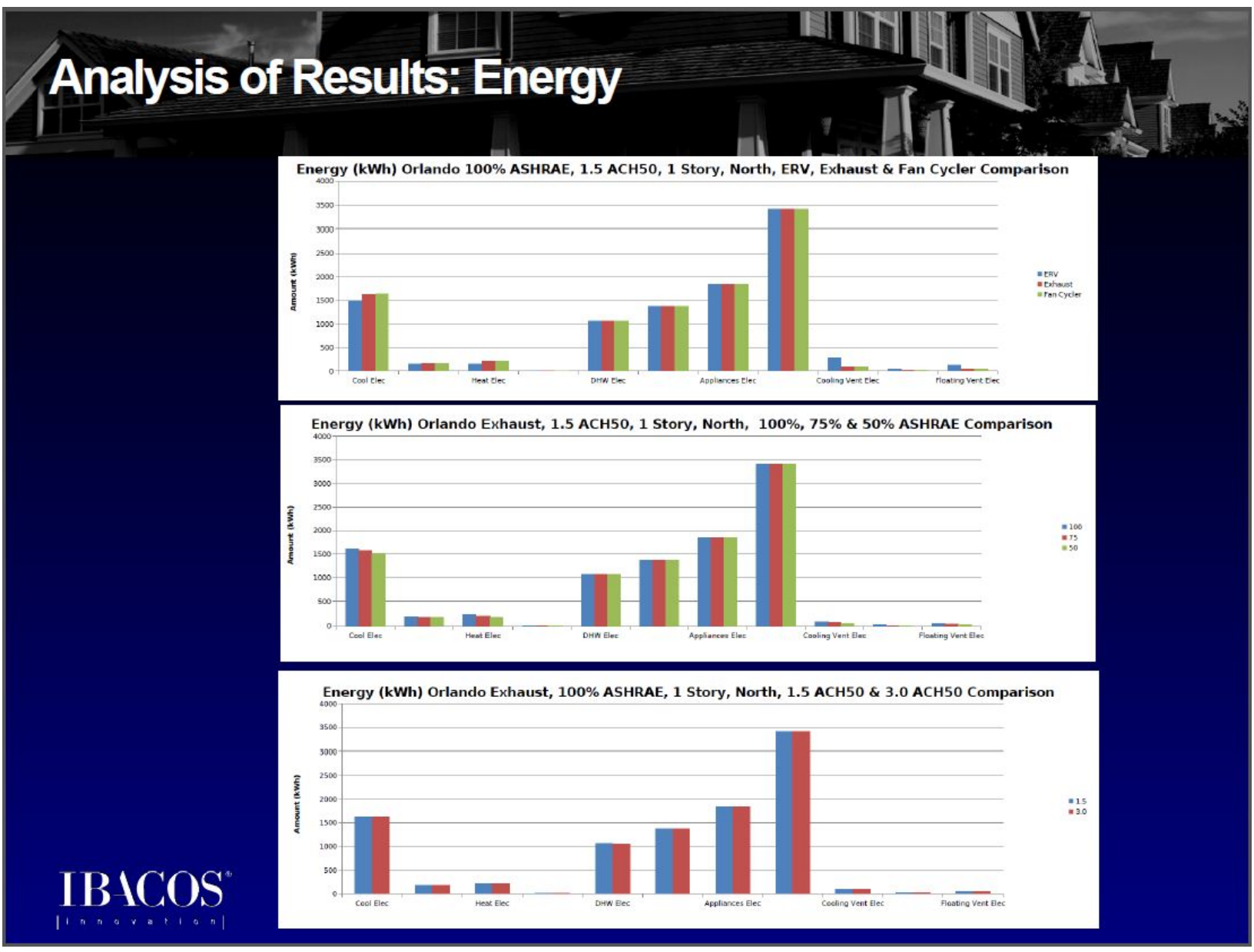

Figure 30. Energy consumption results by ventilation system type, ventilation rate, and building enclosure tightness. 


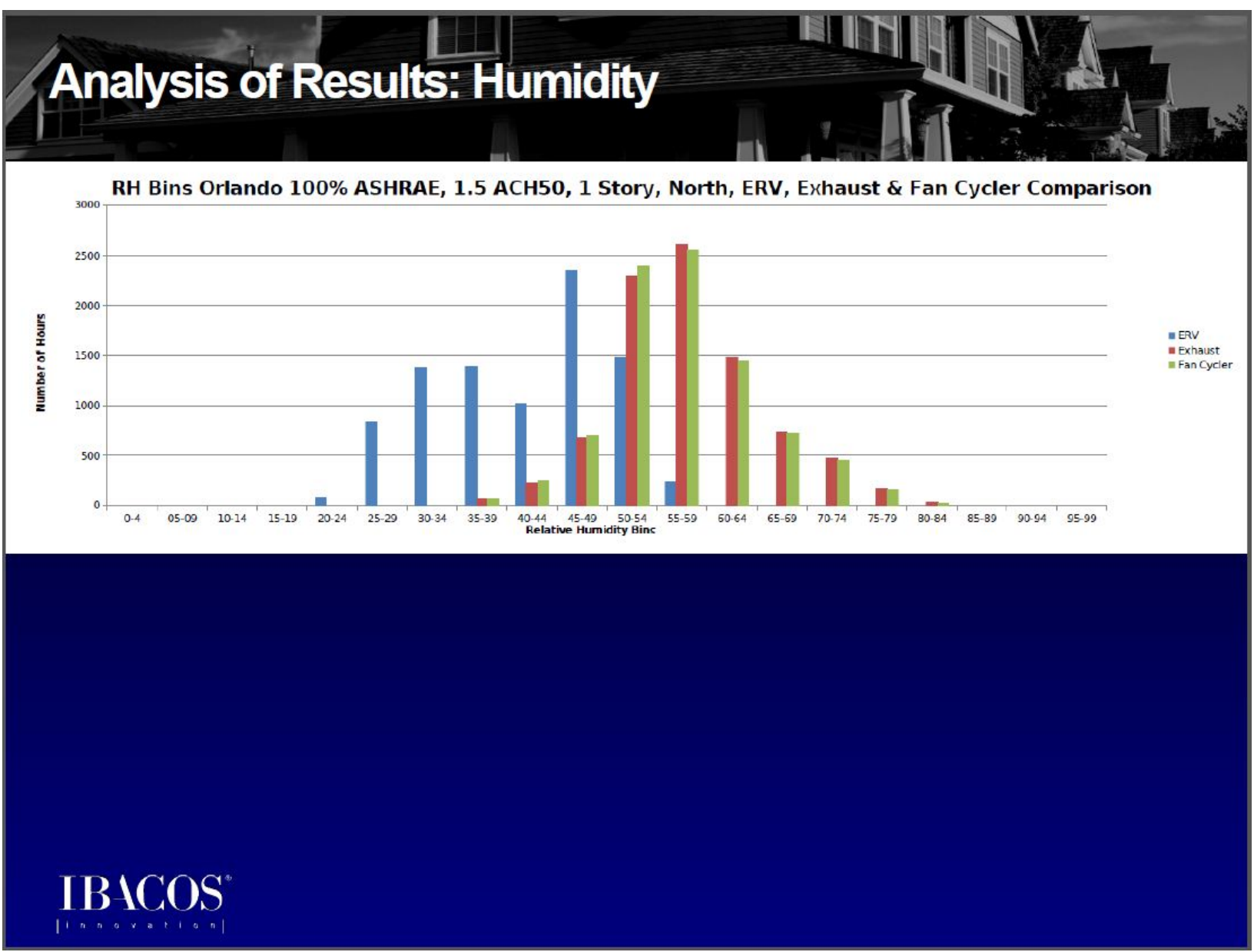

Figure 31. An ERV reduces the number of hours with lowest and highest indoor RH, and a very large reduction in hours above $60 \% \mathrm{RH}$ compared to the FSEC and CDH models.

Analysis was conducted to look at window condensation potential and how that could impact a selected indoor RH limit from a durability perspective. Previous research (Arena et al. 2010) reported the highest occurrence of visible mold or moisture damage was on or around windows and in bathrooms. The window that was modeled was standard double pane with vinyl frame. For that window in Orlando, indoor RH above 75\% shows risk of center-of-glass window condensation, especially during hours when the space conditions were floating between the heating and cooling set points (Figure 32). With a less thermally efficient window frame (nonthermally broken aluminum is common in Florida due to high wind resistance requirements), a lower indoor RH threshold would be needed to avoid condensation on or near the window frame. 


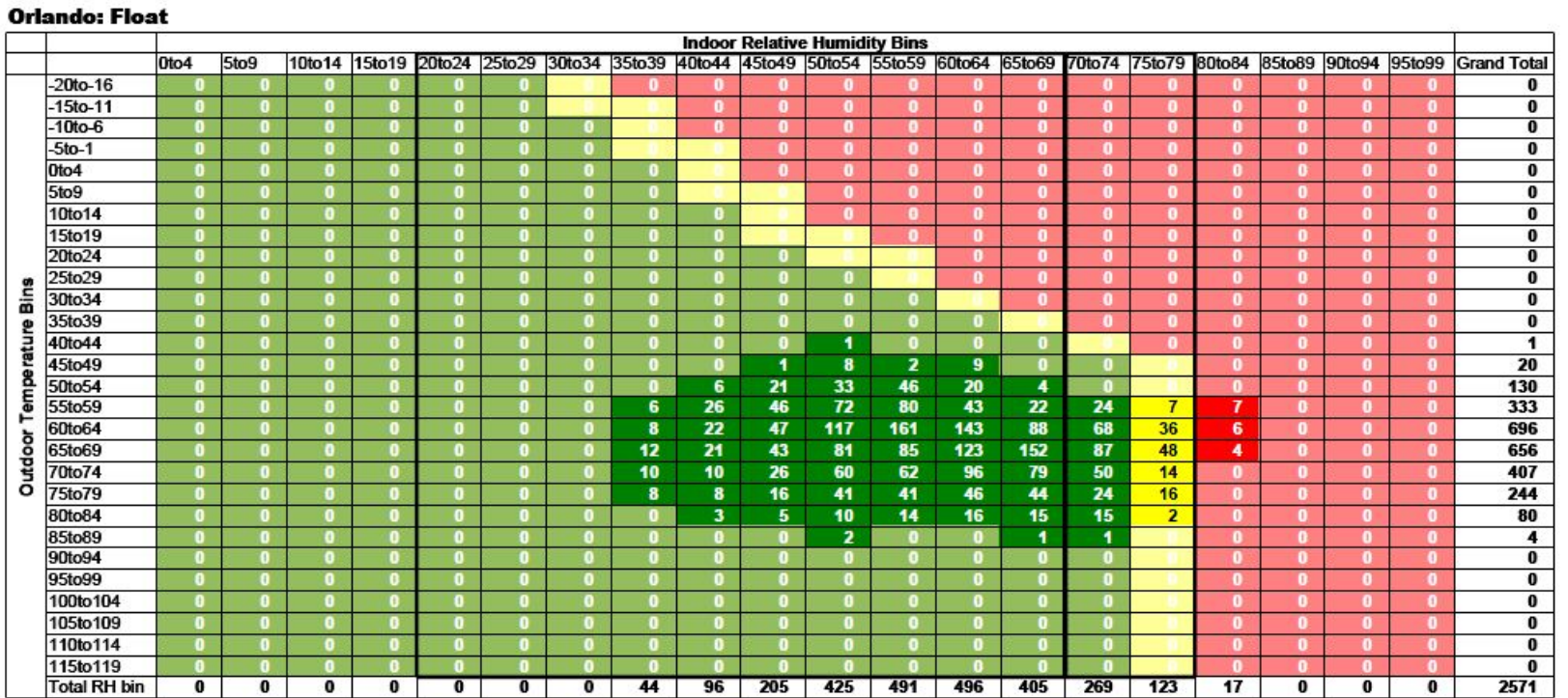

Figure 32. Window condensation potential during Orlando floating hours

\section{Answers to Research Questions}

- What are the important humidity control conclusions from recent residential dehumidification systems modeling, with a wide range of building and equipment sensitivity, using a customized $<2$ minute time-step TRNSYS model with temperature and humidity control?

- Internal moisture generation, internal sensible heat generation, heating setpoint temperature, and air distribution system duct location (inside or outside of conditioned space) are the major influencers of elevated indoor RH in high performance homes in warm-humid climates.

- Mechanical ventilation is a secondary factor in increasing hours above $60 \% \mathrm{RH}$.

- Moisture capacitance is a secondary factor, and lumped moisture mass factors of 10 to 30 times the air mass capacity do not show significant difference in indoor $\mathrm{RH}$.

- Supplemental dehumidification by either a stand-alone dehumidifier, ducted dehumidifier, or gas-fired desiccant dehumidifier (e.g. NovelAire ComfortDry 400 in supply air stream) was effective in eliminating hours over $60 \%$ RH. In Orlando, Miami, and Houston, the difference in total HVAC operating cost between a HERS 70 level house with those systems was $15 \%, 11 \%$, and $1 \%$, respectively. The gas-fired desiccant system showed the lowest operating cost, followed by the ducted dehumidifier and the stand-alone dehumidifier.

- Cooling system enhancement by subcooling condenser reheat was effective in eliminating hours over $60 \%$ RH in Miami and Houston, and nearly so in Orlando. 
- Heat pipe cooling system enhancement was less effective than three degrees overcooling plus low evaporator coil airflow $(210 \mathrm{cfm} /$ ton $)$. Both were more effective in Miami and Houston than in Orlando, but even in Orlando the hours over $60 \%$ RH were reduced by about half (600 down to about 350 on average). However, questions remain as to whether the overcooling can be tolerated from a comfort perspective.

- Two-speed and variable speed cooling systems do not appreciably reduce hours above $60 \% \mathrm{RH}$ unless coupled with lower than standard cooling airflow (cfm/ton).

- What are the important indoor humidity conclusions that can be drawn from recent residential ventilation modeling efforts using the temperature-only control logic of the FSEC EnergyGauge USA program?

- Most of the hours significantly above $60 \% \mathrm{RH}$ occur during floating hours, which occur during fall, winter, and spring in Orlando.

- In Orlando, an ERV nearly eliminated the cooling hours above $60 \% \mathrm{RH}$, but it had little effect on the floating hours above $60 \% \mathrm{RH}$.

○ Hours above $60 \% \mathrm{RH}$ during a particular space conditioning mode (heating, cooling, floating) was a strong function of climate.

- Hours of elevated indoor RH is a strong function of the selected RH limit and climate. For example, in Los Angeles, nearly all of the hours above $60 \% \mathrm{RH}$ are also below $65 \%$ RH, but that is not true for Charleston, Houston, and Orlando.

- Mechanical ventilation, operated at the ASHRAE 62.2-2010 addendum $r$ rate (about 25\% more than before addendum $\mathrm{r}$ ), in a 3 ach50 house, raises the annual median indoor RH by almost 10\% RH compared to a 7 ach50 house without mechanical ventilation in Orlando. However, most of the RH increase due to ventilation is between $60 \%-65 \% \mathrm{RH}$; the hours between $65 \%-75 \% \mathrm{RH}$ mostly remain the same. This indicates that some supplemental dehumidification would be needed in either case anyway.

- Supplemental dehumidification was predicted to be between $\$ 10$ and $\$ 30 / \mathrm{yr}$ for the warm-humid climates of Charleston, Houston, and Orlando, and the marine climate of Los Angeles. However a caveat was provided that indicates that this value is predicated on an operating dehumidifier EF of $1.47 \mathrm{~L} / \mathrm{kWh}$ and recent field data indicates that conventional dehumidifiers operate closer to $0.8 \mathrm{~L} / \mathrm{kWh}$ (Mattison and Korn 2012), which would tend to double this cost. Additionally, dehumidifiers tend to operate on a large humidity deadband, which means that maintaining humidity below $60 \%$ would likely require humidity setpoints near $55 \%$, which would dramatically increase dehumidification costs. 
- What are the important humidity control conclusions from recent residential ventilation modeling efforts using the temperature and humidity control logic of the Energy Plus version of the NREL BEopt program?

- Energy consumption by ventilation system type, ventilation rate, and building enclosure tightness showed relatively small differences in each case compared to total HVAC energy consumption.

- Durability analysis for Orlando, for a standard double pane window with vinyl frame, showed that indoor RH above $75 \%$ risks center-of-glass window condensation, especially during hours when the space conditions are floating between the heating and cooling set points. With a less thermally efficient metal window frame, the risk would be greater.

- How do the results from these different programs compare?

The most important way in which the results differ between the simulation programs is in the frequency and magnitude of elevated indoor RH. For example, in Orlando, the CDH, FSEC, and IBACOS results show hours above $60 \% \mathrm{RH}$ in the range of 1000,2000 , and 3000, respectively. In terms of maximum indoor RH, the $\mathrm{CDH}$ and FSEC results both show about $75 \%$ while the IBACOS results show about $85 \%$. However, in all cases, supplemental dehumidification would be required for high performance, low-energy houses, and the difference in supplemental dehumidification energy would probably be less than $150 \mathrm{kWh} / \mathrm{yr}$ or less than $\$ 20 / \mathrm{yr}$.

The IBACOS ERV modeling using EnergyPlus is suspect of showing too much reduction in elevated indoor humidity hours compared to both the CDH and FSEC models, however, the $\mathrm{CDH}$ model did not model the ERV as a completely separate system from the central system ducts. After a sensitivity run by $\mathrm{CDH}$ is done with an ERV as a completely separate system, the results will be more directly comparable.

- Is it generally agreed that controlling to less than $60 \% \mathrm{RH}$ is the appropriate humidity control point for high performance homes, and why?

It was generally agreed that, a dehumidification control setpoint of 55\%, in order to keep indoor RH from exceeding a $60 \% \mathrm{RH}$ limit, was the correct strategy for high performance, low-energy homes. While it is clear that everything will not fail at once if the indoor $\mathrm{RH}$ goes over $60 \%$, a $60 \% \mathrm{RH}$ limit provides the best practice coverage for providing comfort and durability over a reasonable range of varying factors, such as internal moisture generation rate, and occupant comfort perception and susceptibility to illness stemming from elevated indoor humidity. Included in the variability of internal moisture generation rate is construction moisture drying. It has been BSC's experience that limiting indoor RH to $60 \%$ via supplemental dehumidification is a generic enough limit to remove moisture concerns related to the seasonal timing of building closure and occupancy in warm-humid climates.

- Is it generally agreed that annual hours above $60 \% \mathrm{RH}$ is the appropriate humidity control performance metric to use to compare system performance and to compare 
required supplemental dehumidification energy? Does that metric give generally the same result as looking at 4-hour and 8 -hour events above $60 \% \mathrm{RH}$ ?

It was generally agreed that annual hours above $60 \% \mathrm{RH}$ is the single most appropriate humidity control performance metric to use to compare system performance and to compare required supplemental dehumidification energy. That metric does give generally the same result as looking at 4-hour and 8-hour events above $60 \% \mathrm{RH}$.

- For a range of climates, ventilation systems, and space conditioning equipment in high performance homes, what is the magnitude of hours above $60 \% \mathrm{RH}$, the magnitude of supplemental dehumidification energy required to control to less than $60 \% \mathrm{RH}$, the time of year occurrence of elevated indoor humidity and supplemental dehumidification, and the space conditioning mode (heating, cooling, floating) during which most periods of elevated indoor humidity and supplemental dehumidification occur?

The answers to this question are given in more detail in section 6, Agenda Summaries, but are summarized here. The warm-humid climates of Miami, Orlando, Houston, and Charleston show a clear need for supplemental dehumidification for high performance homes. Without supplemental dehumidification, hours above $60 \% \mathrm{RH}$ were in the range of 800 to 1800 , with hours above $65 \%$ being about half of that. Most of the hours of elevated indoor humidity occur in the mild temperature but humid outdoor conditions of fall and spring, but also occur in winter in Orlando and Miami. A smaller number of hours occur during some summer nights and days-long rainy periods. Few hours above $60 \% \mathrm{RH}$ occur during heating hours. Most hours between $60 \%$ $65 \% \mathrm{RH}$ occur during either cooling or floating hours, and most hours above $65 \% \mathrm{RH}$ occur during floating hours. The supplemental dehumidification energy consumed to keep indoor RH below $60 \%$, taken as the difference in total HVAC cost for the same building with and without supplemental dehumidification, is relatively small. It is in the range of $250 \mathrm{kWh} / \mathrm{yr}$ or less (\$30/yr or less), but necessary to enable deep cuts in sensible heat gain without incurring long periods of elevated indoor RH.

\section{Action Items}

The following action items were discussed at the end of the meeting:

- Continue to do more checking to understand the EnergyPlus moisture modeling differences compared to the FSEC and CDH modeling.

- Add a sensitivity run using the CDH model for an ERV not integrated with the central air distribution system.

- Add a sensitivity run using the CDH model to further detail the difference between ducts in the attic and ducts in the conditioned space, where the attic dew point temperature is increased $10^{\circ} \mathrm{F}$ between 10 am and 1 pm between May 15 and October 15 . 
- Contact Association of Home Appliance Manufacturers (AHAM) to explore the prospect of developing a new residential dehumidifier standard encompassing two test points in addition to the one test point in their existing standard, and reporting of additional test results.

$\circ$ From discussion of Figure 33, the group proposed a new dehumidifier test condition of $75^{\circ} \mathrm{F}$ and $55 \% \mathrm{RH}$ to represent spring/fall part load cooling conditions, and a new test condition of $65^{\circ} \mathrm{F}$ and $50 \% \mathrm{RH}$ to represent basement conditions where avoiding high RH or condensation on cool below-grade concrete walls and floors is needed. These new test conditions could replace the AHAM test conditions or could be in addition to the legacy test condition of $80^{\circ} \mathrm{F}$ and $60 \% \mathrm{RH}$ in the current AHAM standard if considered necessary on a consensus basis, primarily as a transitional measure for comparison to legacy test results. The AHAM test point of $80^{\circ} \mathrm{F} / 60 \% \mathrm{RH}$ is not a common indoor environmental condition for occupied spaces, limiting its usefulness to consumers and designers. Thermodynamics dictate that for the same RH set point, dehumidifier energy consumption will be higher at lower, more common indoor dry-bulb temperatures. NREL reported performance maps of several dehumidifiers at various operating conditions (Winkler et al. 2011).

\begin{tabular}{|l|l|l|l|l|l|l|l|l|}
\hline & & & & & \\
\hline
\end{tabular}

Figure 33. Overview of recommended dehumidifier test conditions. 


\section{References}

ANSI/AHAM DH-1-1992, (Reaffirmation of DH-1-1986), "Dehumidifiers." The Association of Home Appliance Manufacturers' Approved as an American National Standard. March 25, 1992. Published by Association of Home Appliance Manufacturers, 1111 19th Street, NW Suite 402, Washington, DC 20036, 202/872-5955.

ASHRAE Standard 160-2009, Criteria for Moisture-Control Design Analysis in Buildings.

ANSI/ASHRAE Standard 55-2010, Thermal Environmental Conditions for Human Occupancy.

Arena, L. B.; Karagiozis, A.; Mantha, P. (2010). "Monitoring of Internal Moisture Loads in Residential Buildings - Research Findings in 3 Different Climate Zones." Thermal Performance of the Exterior Envelopes of Whole Buildings XI, Clearwater Beach, Florida, December. BETEC, ASHRAE, ORNL.

Balaras, C.A. (2007). "HVAC and indoor thermal conditions in hospital operating rooms". Energy and Buildings 39 (4): 454.

BSC (2004). "Results of Advanced Systems Research, Deliverable Number 5.C.1" Project 3 Supplemental Humidity Control Systems, pg. 8-10 of Final Report to U.S. Dept. of Energy under Task Order No. KAAX-3-32443-05 under Task Ordering Agreement No. KAAX-3-32443-00, pg. 8-10, October 29. Midwest Research Institute, National Renewable Energy Laboratory Division, Golden, CO.

BSC (2006). "Systems Engineering Approach To Development Of Advanced Residential Buildings, 11.B.1 Results Of Advanced System Research.” Project 6 - Enhanced Dehumidifying Air Conditioner of Final Report to U.S. Dept. of Energy under Task Order No. Kaax-3-32443-00 under Task Ordering Agreement No. Kaax-3-32443-10. Midwest Research Institute, National Renewable Energy Laboratory Division, 1617 Cole Boulevard, Golden, CO.

BSC (2007a). "Systems Engineering Approach To Development Of Advanced Residential Buildings, 14.B.1 Results Of Advanced Systems Research”, Project 1 - Enhanced Dehumidifying Air Conditioning of Final Report To U.S. Dept. of Energy under Task Order No. Kaax-3-32443-14 under Task Ordering Agreement No. Kaax-3-32443-00. Midwest Research Institute, National Renewable Energy Laboratory Division, 1617 Cole Boulevard, Golden, CO.

BSC (2007b). "Whole House Ventilation System Options - Phase 1 Simulation Study." ARTI Report No. 30090-01, Final Report, March. Air-Conditioning and Refrigeration Technology Institute, Arlington, VA.

Henderson, H.I.; Rengarajan., K.; Shirey, D.B. (1992). "The Impact of Comfort Control on Air Conditioner Energy Use in Humid Climates”, ASHRAE Transactions Vol. 98 Part 2. 
Henderson, H.; Shirey, D.; Raustad, R. (2007). "Development of a New Climate-Sensitive Air Conditioner (Task 4): Simulation Results and Cost Benefit Analysis”, FSEC-CR-1716-07, Cocoa: Florida Solar Energy Center.

Henderson, H. and Rice, C.K. (2008). "Analysis of Dehumidification Options in Standard Practice and Near-Zero Energy Homes", Oak Ridge National Laboratory Report ORNL/TM2008/64.

Mattison, L. and Korn, D. (2012). "Dehumidifiers: A Major Consumer of Residential Electricity." 2012 ACEEE Summer Study on Energy Efficiency in Buildings. American Council for an Energy Efficient Economy, Washington D.C.

Rudd, A.; Lstiburek, J.; Ueno, K..(2003). "Residential dehumidification and ventilation systems research for hot-humid climates," Proceedings of 24th AIVC and BETEC Conference, Ventilation, Humidity Control, and Energy, Washington, US, pp.355-60. 12-14 October. Air Infiltration and Ventilation Centre, Brussels, Belgium.

Rudd, A.; Lstiburek, J.; Ueno, K. (2005). Residential dehumidification systems research for hothumid climates. U.S. Department of Energy, Energy Efficiency and Renewable Energy, NREL/SR-550-36643. www.nrel.gov/docs/fy05osti/36643.pdf.

Rudd, A.; Henderson, H.. (2007). "Monitored Indoor Moisture and Temperature Conditions in Humid Climate U.S. Residences.” ASHRAE Transactions (17, Dallas 2007). American Society of Heating Refrigeration and Air-Conditioning Engineers, Atlanta, GA.

Shirey, D.B.; Henderson, H.I.; and Raustad, R. (2006). "Understanding the Dehumidification Performance of Air-Conditioning Equipment at Part-Load Conditions", Final Report, FSEC-CR1537-05, Cocoa: Florida Solar Energy Center.

Winkler, J.; Christensen, D.; Tomerlin, J. (2011). "Laboratory Test Report for Six ENERGY STAR ${ }^{\circledR}$ Dehumidifiers.” Technical Report NREL/TP-5500-52791, National Renewable Energy Laboratory, Golden, CO.

Wolkoff, S.and Kjaergaard, K. (2007). "The dichotomy of relative humidity on indoor air quality". Environment International 33 (6): 850. 
buildingamerica.gov

u.s. DEPARTMENT OF Energy Efficiency \& ENERCY Renewable Energy 